\title{
Scientific Programme of the 10th Canadian Congress of Neurological Sciences 10e Congres Canadien des Sciences Neurologiques
}

\author{
London, Ontario \\ June 18 - 211975 .
}

\section{PARTICIPATING SOCIETIES}

Canadian Neurological Society

Canadian Neurosurgical Society

Canadian Society of Electroencephalographers, Electromyographers and Clinical Neurophysiologists

Canadian Chapters of the Society for Neuroscience

Canadian Association of Neurological and Neurosurgical Nurses

\section{SOCIETES PARTICIPANTES}

Société canadienne de neurologie

Société canadienne de neurochirurgie

Société canadienne d'electroencephalographistes, electromyographistes et des neurophysiologistes cliniques

Delegation canadienne de la société neuroscientifique

Association canadienne des infirmières en neurologie et neurochirurgie

\section{OFFICERS OF CONGRESS}

OFFICIERS DU CONGRES

President/Président: Dr. Arthur J. Hudson

Director/Directeur: Dr. Bruce Hendrick

\section{ADVISORY COMMITTEE}

Dr. Henry J. M. Barnett

Dr. Hugh W. K. Barr

Dr. Charles F. Bolton

\section{SCIENTIFIC PROGRAMME} Chairman/Président:

Dr. H. W. K. Barr

Dr. J. J. Hardy

\section{CONSULTANTS}

Dr. J. M. Allcock

Dr. M. D. Haust

\section{LOCAL ARRANGEMENTS}

Dr. J. M. Allcock

Dr. A. L. Amacher

Dr. M. Ball

Dr. W. T. Blume

Dr. J. D. Brown

Dr. W. F. Brown
Dr. J. P. Girvin

\section{COMITE CONSULTATIF}

Dr. Charles G. Drake

Dr. Katherine Metrakos

PROGRAMME SCIENTIFIQUE

Dr. H. J. M. Barnett

Dr. A. Kertesz

Dr. R. G. Lee

CONSULTANTS

Dr. G. G. Hinton

Dr. J. C. E. Kaufmann

\section{ARRANGEMENTS LOCAUX}

Dr. R. Coates

Dr. G. G. Ferguson

Dr. J. J. Gilbert

Dr. N. Jaatoul

Dr. W. P. McInnis

Dr. D. W. Paty

\section{COMITE FEMININ}

\section{LADIES COMMITTEE}

Neurological Sciences, Faculty of Wives of the Department of Clinical Neurologica
Medicine, The University of Western Ontario.

\author{
OFFICERS OF PARTICIPATING SOCIETIES \\ OFFICIERS DES SOCIETES PARTICIPANTES \\ Canadian Neurological Society \\ Société canadienne de Neurologie \\ President/Président \\ Past-President/Ex-Président \\ Vice-President/Vice-Président \\ Secretary-Treasurer/Secretaire-Trésorier \\ Dr. A. J. Hudson \\ Dr. E. Ashenhurst \\ Dr. H. M. J. Barnett \\ Dr. F. Andermann \\ COUNCILLORS/COUNSEILLERS \\ Dr. R. G. Lee \\ Dr. H. B. Dinsdale \\ Dr. C. A. Simpson \\ Dr. N. Giard \\ Dr. J. K. Murray \\ Dr. R. F. Nelson
}

Canadian Neurosurgical Society

Société Canadienne de Neurochirurgie

President/Président

Past-President/Ex-Président

Vice-President/Vice-Président

Secretary-Treasurer/Secretaire-Trésorier

COUNCILLORS/CONSEILLERS

Dr. J. G. Giroux

Dr. R. Hansebout

Dr. R. G. Vanderlinden

Dr. E. B. Hendrick

Dr. J. G. Stratford

Dr. G. B. Thompson

Dr. H. W. K. Barr

Dr. L. J. Clein

Dr. W. S. Huestis

Dr. P. D. Moyes

Canadian Society of Electroencephalographers, Electromyographers and Clinical Neurophysiologists

Societe Canadienne d'Electroencephalographistes,

Electromyographistes et des Neurophysiologistes Cliniques

President/Président

Dr. K. Metrakos

Past-President/Ex-Président

D. M. Low

Vice-President/Secretary

Vice-Président/Secretaire

Dr. M. Brandstater

Treasurer/Trésorier

Dr. D. McGreal

COUNCILLORS/CONSEILLERS

Dr. A. Eisen

Dr. J. Humphreys

Dr. R. Broughton

Canadian Chapters of the Society for Neuroscience Délégation Canadienne de la Société Neuroscientifique

Eastern Chapter

Délëgation de l'est

President/Président

Past-President/Ex-Président

Vice-President/Vice-Président

Secretary/Secretaire

Dr. J. Diamond

Dr. K. Krnjevic

Dr. L. Poirier

Dr. G. Mandl

B.C. Chapter

Délégation de B.C.

President/Président

Past-President/Ex-Président

Dr. H. C. Fibiger

Past-President/Ex-Pres
Secretary/Secretaire

Dr. P. McGeer

Dr. M. Corcoran 
Canadian Association of Neurological and Neurosurgical Nurses Association Canadienne des Infirmières en Neurologie et Neurochirurgie President/Président Vice-President/Vice-Président Past-President/Ex-Président Secretary/Secretaire Treasurer/Trésorier

\section{Congress Headquarters}

Lieu de congres

University Hospital, London, Ontario

Distinguished Scientific Guest of the Congress

Invité Distingué du Congres

Professor Charles G. Phillips

University Laboratory of Physiology

Oxford University

OXFORD, England

\section{Honored Guest Speaker}

Conferencier Invité

Dr. Albert W. Trueman, 407 Wood Avenue, Rockcliffe, Ottawa, Ontario

\section{Neurosurgical Guest Speaker}

Neurochirurgie Conferencier

Dr. Irving S. Cooper, 4422 - 3rd Avenue, New York, N.Y. 10457

\section{SCIENTIFIC PROGRAMME}

Opening of Congress and Presidential Address - A. J. Hudson, President

Clinical-Biochemical Investigation in Neurology: Myotonia Dystrophica

K. G. McKenzie Memorial Award

The Reactivity of Canine Cerebral Arteries to $\mathrm{O}_{2}$ and $\mathrm{CO}_{2}-\mathrm{P}$. Steinbok, Vancouver

Prevention of Experimental Allergic

Encephalitis with the Anti-Encephalitogenic

Spinal Cord Protein, SCP

C. F. C. MacPherson and Sui-Lan Yo, London, Ontario

Treatment of guinea pigs with the $\boldsymbol{\beta}$-form of the bovine spinal cord protein ( $\boldsymbol{\beta}-\mathrm{SCP})$ prevented them from developing clinical and histologic signs of experimental allergic encephalitis (EAE) when they were subsequently sensitized with an excessive disease inducing injection of whole bovine spinal cord (J. Immun., 110, 1371, 1973). The present report will describe protection experiments using bovine $\boldsymbol{\gamma}$-SCP for pretreatment and excessive doses of purified bovine myelin basic protein (BP) for induction of EAE. The results confirmed the initial findings with respect to prevention of clinical EAE and suggested that protection against EAE might be related to the anti-SCP antibody level at the time of challenge. Immunodiffusion studies using a rabbit anti-BP serum and a rabbit anti-SCP serum showed that $B P$ and $S C P$ are immunochemically distinct proteins; moreover, the bovine BP and SCP used for these experiments were free from contaminants detectable by immunodiffusion tests. Thus, the protection afforded by pretreatment with SCP can not be ascribed to contamination of SCP with BP or to any immunochemical similarity to BP. The degree of protection afforded by various amounts of anti-SCP antibody before and 2 weeks after challenge with BP will described.

\section{Inhibition of Lymphocyte Migration in Multiple Sclerosis Richard Armstrong, Toronto, Ontario}

This study is an attempt to determine the usefulness of a migration inhibition test in monitoring the activity of the disease process in multiple sclerosis.

A group of 20 patients with MS were tested at monthly intervals for a period of 6-8 months. Two antigens prepared from Myelin (encephalitogenic on basic protein (BP) and a lipoprotein $\left(\mathrm{N}_{2}\right)$ were used in the migration test ${ }^{-d e s c r i b e d}$ by Soberg.
To date only 2 patients have developed exacerbation with clinically documented signs. In both, significant inhibition of migration occurred in association with the attack. In 8 patients migration inhibition developed without associated exacerbation. 9 patients showed no inhibition during the course of the study although some of these had progressive neurologic disease.

The responses to $\mathrm{N}_{2}$ will be discussed in relation to the response of normals to this antigen.

The potential and limitations of this technique as a laboratory measurement of the activity of the process of MS will be discussed.

\section{Direct Leukocyte Migration Inhibition by Myelin Basic Protein in Attacks of Multiple Sclerosis \\ William Sheremata and Henry Triller, Montreal, Quebec}

Cell-mediated hypersensitivity to central nervous system myelin has long been assumed to be important in the pathogenesis of multiple sclerosis. In vitro techniques such as the indirect macrophage migration inhibition factor (MIF) assay have demonstrated evidence of such hypersensitivity. The complexity of the technique and the delay before results are available prompted us to utilize the direct leukocyte migration inhibition assay and attempt to obtain data of similar significance.

Seven normal subjects, nine multiple sclerosis (MS) patients within three weeks of an acute exacerbation, and seven others with MS one to six months after onset were studied for evidence of cell-mediated hypersensitivity in myelin basic $A_{1}$ protein. Three stroke patients and four acutely-ill subjects with the Guillain-Barré Syndrome were studied as additional controls. Peripheral leukocytes obtained by leukophoresis were packed into capillary tubes, and allowed to migrate out onto glass in the presence or absence of myelin A1 protein. Cells of patients within three weeks of an MS attack gave a mean migration of $68 \pm 9 \%$, and those one to six months after onset $93 \pm 19 \%$. The whole group multiple sclerosis patients gave a mean migration of $87 \pm 14$, those with the Guillain Barré $112 \pm 11$, and the stroke patients $112 \pm 8$. Results of the acutely-ill MS patients were significant to the $P==0.005$ level. The other results fail to reach statistical significance.

Data obtained using the direct leukocyte migration assay is similar to that previously obtained using the MIF assay and shows that MS lymphocytes elaborate a second mediator in response to myelin $A_{1}$ protein. The elaboration of this second mediator, leukocyte inhibitory factor (LIF), occurs during the acute exacerbations of illness and strengthens the evidence that sensitization to this potent encephalitogen occurs simultaneously with exacerbations of clinical illness.

\section{HL-A Types, Measles Antibodies and Clinical Course in Multiple Sclerosis}

D. W. Paty, J. Furesz, C. G. Rand and C. Stiller, London, Ontario

The histocompatibility antigens (HL-A) and measles antibody levels have been determined in 136 Caucasian Canadian Multiple Sclerosis (MS) patients and in several different control series. There is an increased frequency of HL-A types $3,7, \&$ W-18 in this MS population. This group of patients $(3,7, \& \mathrm{~W}-18)$ has a significantly higher mean titre of measles antibodies as compared to MS patients not carrying these antigens. The total MS group also has significantly higher measles antibodies than sibling controls and matched controls. Antibody levels do not vary with age. Analysis of the clinical course of these patients in relation to the above data has shown the following:

1) $93 \%(14 / 15)$ of patients with age of onset below 20 carry the HL-A $3,7, \&$ W-18 antigens.

2) The initial symptoms of diplopia and gait disturbances are more common in the $3,7, \mathrm{~W}-18$ group.

3) Patients of all groups with older age of onset have a more progressive clinical course.

4) $76 \%$ of patients with a more benign course are female and this was more common in the 'others' group (21\%).

5) Males in all groups had a much more rapidly progressive clinical course and this was most marked in males in the 'others' group $(\mathrm{p}=<$ 0.05 ).

The relationship of HL-A types and measles antibodies to MS seems to be well established but the correlations with the clinical course of the disease seem to be complex and in some instances sex related. 


\section{Measles Immunity and Sensitization to Myelin A1 Protein} in SSPE and Multiple Sclerosis

William Sheremata and Gordon Watters, Montreal, Quebec

Subacute sclerosing panencephalitis (SSPE) is now recognized as an unusual measles virus infection of the human nervous system. Recent indirect evidence has also implicated measles in multiple sclerosis (MS). Altered immune responses have been postulated as a predispos. ing factor but results of investigations of cellular immunity to measles have been inconclusive. This report represents a prospective study of cellular immunity to measles and basic myelin protein in SSPE and MS.

Three children with SSPE, 12 normal subjects, and 12 patients with multiple sclerosis were studied utilizing the macrophage migration inhibition factor (MIF) assay with measles, rubella and basic myelin ( $\left.A_{1}\right)$ protein antigens. SSPE patients inhibited a migration index (MI) of 43 \pm 10.6 for measles, $35 \pm 8$ for rubella and $53 \pm 28.7$ for A1 protein. MS patients exhibited values of $103 \pm 10.6,93 \pm 19.7$, and $82 \pm 28.4$; whereas normals gave values of $69 \pm 22.7,79.6 \pm 25.6$ and $101 \pm 6.5$ for measles, rubella, and $A_{1}$ protein respectively.

The results of this study show increased cellular immunity to measles and rubella in SSPE as compared with normals and a complete absence of immunity to measles antigens in multiple sclerosis. Patients with multiple sclerosis showed hypersensitivity to $\mathrm{A}_{1}$ protein during clinical attacks which was not associated with changes in immunity to measles, whereas all SSPE patients showed a significant response regardless of stage of illness.

\section{Complex Glia Specific Antigen (GSA) \\ in Normal and Neoplastic Human Brain Immunofluorescence Studies \\ B. Lach, London, Ontario B. Lauk, Lodz, Poland}

The GSA was isolated from normal brain obtained at autopsy. Brain was homogenized in water and $0.9 \% \mathrm{NaCl}$ at $\mathrm{pH} 7.2$, and $\mathrm{GSA}$ was obtained from the soluble fraction by repeated precipitation with $(\mathrm{pH}$ $4.0)$ and dissolving in (pH 7.2) saturated $\left(\mathrm{NH}_{4}\right)_{2} \mathrm{SO}_{4}$ at $4^{\circ} \mathrm{C}$. Rabbits were immunized every fourth day for 8 weeks with $0.5 \mathrm{ml}(0.8 \mathrm{mg}$. proteins $/ \mathrm{ml}$.) of GSA mixed with Freund's adjuvant. Anti-sera were absorbed with human plasma and homogenates of kidney, liver, spleen, and muscles. $\gamma$-globulins were precipitated with $33 \%\left(\mathrm{NH}_{4}\right)_{2} \mathrm{SO}_{4}$ and used for examination in agar diffusion (AD), immunoelectrophoresis (IME) and immunofluorescence (IMF) (sandwich technique). Specific antiserum showed one or two precipitation lines with human brain homogenates in AD, and three lines in IME (alfa2 and albumin area). Specificity was not species restricted. In the normal brain IMF was limited to the neuropil and to the interfascicular compartment of white matter. Of tumors examined, the strongest, diffuse and fibrillar or reticular intracytoplasmic IMF was present in astrocytomas; it decreased slightly to moderately with an increasing anaplasia of these tumors. In oligodendrogliomas, IMF was usually restricted to the cellular membranes, and it decreased considerably with morphological evidence of increasing malignancy. In glioblastoma multiforme mixed and anaplastic gliomas, IMF was present only in some areas of tumors, and usually was absent from immature cells. All other neoplasms examined, i.e., ependymoma, plexus papilloma, medulloblastoma, meningiomas and metastatic carcinomas - were negative.

\section{Myasthenia Gravis: A Study of HLA Types and Steroid Therapy}

Richard A. Dickson and Ludmila R. Zeldowicz, Vancouver, British Columbia

During the past year several reports have appeared in the literature which suggest a correlation of Histocompatible Tissue Antigens (HLA Type) with Myasthenia Gravis and specifically with the pathology of the thymus gland. Also of recent interest is the use of alternate day high dose Prednisone therapy in Myasthenia. To corroborate these studies a review was made of patients in the Vancouver area with well documented Myasthenia Gravis.

Patients were interviewed with particular emphasis on the onset and course of the disease and the present functional status. Pathologic reports of thymus tissue were collected. All patients had HLA Typing performed at the Tissue Typing Laboratory of the Vancouver General
Hospital. A total of eighty cases of Myasthenia Gravis were reviewed. In this group were thirty-four who had a thymectomy. These included six cases with thymoma and twenty-eight in which thymic hyperplasia was demonstrated.

In reviewing these patients particular attention was given to the course of those patients treated with steroids. There were eleven patients who were treated with alternate day high dose Prednisone. The response of these patients and the relationship to duration and severity of disease, age, sex, and thymic pathology was ascertained. An attempt was made to correlate the HLA Type with steroid responsiveness.

\section{Nerve Repair - Interfascicular Suture vs. Interfascicular Graft}

Bert Bratton, David Kline and Alan Hudson, New Orleans, U.S.A. and Toronto, Ontario

The work of Millesci has had a considerable impact on the management of peripheral nerve injuries. He advises interfascicular grafting, even in cases in which there is no difficulty in doing a conventional end-to-end suture. The basis for this approach is the concept that tension at the suture line is the most deleterious factor. This is in direct contrast to established practice which is based on World War II reports that gaps of up to 8 to 10 centimeters could be overcome by conventional means with direct end-to-end suturing without any influence on the clinical results. Nerve grafts, with two suture lines, were found to give inferior results.

The tibial nerves of 12 chimpanzees were cut and the fascicles dissected out under the operating microscope. On the control side the fascicles were immediately sutured using 100 nylon. On the experimental side one centimeter interfascicular sural nerve grafts were interposed between fascicles. Animals were evaluated at 4, 6, 9 and 12 month intervals. Measurements included evoked nerve action potential, EMG, single twitch, tetanic response with supermaximal stimulus, taken before surgery and at the time of sacrifice. Serial biopsies were examined by light and electron microscopy. Although one of the methods was found to be adequate the other was found to be consistently better in every animal examined. The electrophysiological data and electron microscope photographs will be presented. The practical application of these results in clinical practice will be discussed.

\section{Effect of Duration of Compression on Recovery from Acute Compression Injury of Primate Spinal Cord}

Charles H. Tator, Alan N. Sandler and Virginia E. Edmonds, Toronto, Ontario

It has previously been shown in this laboratory that hypothermic or normothermic perfusion improved the recovery of the spinal cord in monkeys injured by the circumferential extradural cuff technique with the cuff inflated to $350 \mathrm{~mm} \mathrm{Hg}$ for 5 minutes, but that at $400 \mathrm{~mm} \mathrm{Hg}$ for 5 minutes only normothermic perfusion improved recovery. The present experiments were designed to determine the effect of the duration of compression on the recovery from acute compression injury of primate spinal cord.

Forty rhesus monkeys were divided into two groups of twenty. One group was injured with the cuff at $150 \mathrm{~mm} \mathrm{Hg}$ for 60 minutes and the other at $150 \mathrm{~mm} \mathrm{Hg}$ for 180 minutes. Half the animals in each group received normothermic perfusion with Elliott's ' $B$ ' solution beginning three hours after the onset of trauma and continuing for three hours. To ensure objective assessment, treated and control animals were selected at random after injury, and motor recovery was assessed 'blindly' for 12 weeks after injury without the assessor knowing how an animal had been treated.

The results showed that normothermic perfusion was of no value for animals injured at $150 \mathrm{~mm} \mathrm{Hg}$ with the cuff in place for either 60 or 180 minutes of compression. This indicates that perfusion is only beneficial for injuries in which the duration of compression is short. The results also showed that the 20 monkeys injured for 60 minutes had a significantly better recovery than those injured for 180 minutes $\left(x^{2} p<.00001\right)$, which indicates that duration of cord compression in the first few hours after injury is an extremely important factor determining recovery. 


\section{Notre Expérience avec Trente Cas de Stimulateur Médullaire} Michel A. Copty, St. Foy Québec

Dans cette présentation nous allons discuter de l'expérience du Service de neurochirurgie à l'Hôpital de l'Enfant-Jésus avec les cas qui ont été opérés à cet hôpital.

Depuis les trois (3) dernières années trente appareils soit le stimulateur médullaire furent installés. Le choix de nos patients fut laborieux et assez sévère. Tous ces patients avaient été vus, investigués et suivis à la clinique de la douleur. Cette clinique est dirigée par un neurochirurgien, un neuropsychologue et un anesthésiste.

Pour sélectionner un patient pour l'installation du stimulateur médullaire, celui-ci doit être très bien investigué et connu à la clinique depuis plusieurs mois. Pour donner une idée sur le choix des patients, les trente patients pour lesquels on a installé l'appareil furent sélectionnés entre 500 patients qui se sont présentés pour problème douloureux chronique dont l'état nécessitait un traitement ou une chirurgie pour la douleur.

Lorsque les patients furent choisis pour cet appareil on a tenté de diversifier les pathologies choisies. On avait plusieurs cas de cancer, quelques cas d'arachnoidite post-chirurgicale, des cas de membre fantôme, deux cas d'hémiplégie spastique d'origine vasculaire avec syndrome douloureux, deux cas de paraplégie traumatique et un cas de douleur thoracique post-herpétique.

On a installé l'appareil six fois dans la région cervicale, six fois dans la région thoracique haute et 18 fois dans la région dorsale basse.

Durant cette présentation nous discuterons des problèmes que nous avons rencontrés au point de vue technique, les complications per et post-opératoires, les problèmes tardifs de cet appareil et les réinterventions chez nos patients. Egalement, nous discuterons des résultats en général de cette intervention et de l'appareil, et nous donnerons notre opinion sur les indications d'installer le stimulateur dans la forme actuelle chez des patients porteurs de pathologie bénigne non cancéreuse et qui ont un bon pronostic pour vivre plusieurs années.

\section{Transcutaneous Electroanalgesia in the Treatment of Chronic Pain}

R. G. Vanderlinden, Toronto, Ontario

Since the 1890's when it was first reported that pain could be modified by electric current applied to the skin, chiropractors, naturopaths and physiotherapists have used this method of treatment. The observations of Sweet and Wall that chronic pain was relieved by stimulating peripheral nerves and the development of sophisticated instrumentation, however, has rekindled interest in transcutaneous electroanalgesia.

We have evaluated the effects of transcutaneous electrical stimulation using a compact, solid state, battery operated generator (Neuromod ${ }^{1}$ Stimulator) on $\mathbf{4 0}$ patients suffering a variety of chronic pain conditions. Most patients had undergone a standard pain study in hospital to categorize the pain as primarily physiogenic or psychogenic in origin.

The results of this study indicate that $60 \%$ of patients with physiogenic pain obtained worthwhile relief from electroanalgesia whereas only $12 \%$ of patients with a diagnosis of psychogenic pain were relieved. Approximately one third of patients in each group noted no relief of their pain. Of special interest, $55 \%$ of the psychogenic pain group complained of aggravation of pain or found the stimulation unpleasant whereas only $10 \%$ of the physiogenic group reported this reaction. This observation suggests that electroanalgesia may have diagnostic as well as therapeutic applications.

The only complication has been skin irritation beneath the electrodes and the tape. Considering the difficult type of pain problems this group of patients represents, these results are most encouraging.

\section{Proximal Occlusion of the Anterior Cerebral Artery for Anterior Communicating Aneurysm}

A. D. Hockeley and E. B. Hendrick, Toronto, Ontario

The correct management of ruptured anterior communicating aneurysms is a source of anxiety to all neurosurgeons. Following Dott's successful proximal anterior cerebral artery occlusion in 1944, several authors notably Logue have reported their results with the same operation. Although McKissock in 1965 challenged the view, it soon became accepted that operative treatment was better than conservative, particularly for the less ill patients.
This paper reports the experience in the management of subarachnoid hemorrhage due to anterior communicating artery aneurysms over 10 years in Cambridge, England, where proximal anterior cerebral artery occlusion has been the method of choice.

From December 1961 to April 1973, 372 patients were admitted, of whom 124 patients had an aneurysm arising from the anterior communicating artery at its junction with the anterior cerebral artery. When the angiogram showed the aneurysm to be filled from one side and provided there was good cross flow; and provided patients were in Botterell grades 1-3, proximal occlusion of the main supplying anterior cerebral artery was the preferred treatment.

In this series, patients were treated as follows:

Proximal Anterior Cerebral Artery Occlusion

Conservative

Direct Surgery

Evaculation of Subdural Hematoma Only

Decompressive Craniotomy

The reasons for conservative treatment included: poor clinical condition of the patient, marked angiographic spasm, multiple aneurysms, pulmonary embolism and refusal of surgery.

Results

\begin{tabular}{lccc}
\hline & Proximal Occlusion & Direct Surgery & Conservative \\
\hline Patients & 68 & 15 & 39 \\
Deaths & 7 & $\frac{2}{13.3 \%}$ & $\frac{27}{69 \%}$ \\
Mortality & $10.3 \%$ & $13 \%$
\end{tabular}

The mortality following anterior cerebral artery occlusion was $10.3 \%$ and patients have been followed up from 2-10 years. Two patients are known to have died from recurrent SAH at 7 months and 4 years. Out of 68 patients, $58(85 \%)$ are known to be leading normal family lives and able to do work. Although there is little statistical difference in the mortality between the two surgically treated groups, there is a greater risk of acquired deficit in those undergoing direct surgery.

The chief merit of proximal anterior cerebral artery occlusion however is its technical simplicity and for this reason, we believe it still has a place in the treatment of these aneurysms.

\section{Surgical Treatment of Subarachnoid Hemorrhage in the Case of Multiple Aneurysms}

J. P. Girvin, C. G. Drake and A. H. Zidan, London, Ontario

From a perusal of the literature it is obvious that controversy still exists with respect to how patients should be treated who harbour multiple intracranial saccular aneurysms. There would seem to be little controversy as to whether or not the ruptured aneurysms should be treated, but as to whether the unruptured associated aneurysm should be treated and if so, how they should be treated remain as contentious points.

The important issue, which remains unsettled, is whether or not the natural history of unruptured aneurysms carries with it higher risks of morbidity and mortality than that associated with surgical obliteration of the unruptured aneurysm.

Over 120 patients with multiple aneurysms have been treated surgically in the neurosurgical unit in London, Ontario. These cases have been analyzed in various ways including patient grade on admission and prior to surgery, death during the 'waiting period', time to operation, age, and hypertension. In addition the surgical treatment has been analyzed with respect to size of aneurysm, site of aneurysm regarding various combinations of bilaterality and posterior fossa-anterior fossa sites, and the question of 'staged' procedures versus a single procedure for the obliteration of the aneurysms.

Based on the observations, admittedly analyzed retrospectively, along with follow-up where possible, it is suggested that in cases of multiple aneurysms the associated unruptured aneurysms should be obliterated as well as the ruptured aneurysms, if they have reached a critical size. The data lend support to the fact that such 'unruptured' aneurysms are not so innocent as perhaps thought by some. The analyses do not satisfactorily resolve the question of whether aneurysms should be operated on at a single sitting or by staged procedures. 
The Percutaneous Treatment of Carotid Cavernous Fistula with Preservation of the Carotid Artery

Eric W. Peterson, John D. Valberg and Enrique Ventureyra, Ottawa, Ontario

Earlier experience with the percutaneous treatment of a carotid cavernous fistula in a young male had convinced us that the cavernous sinus could be thrombosed. We introduced an insulated copper wire with an exposed tip into the cavernous sinus by means of the superior orbital vein. Progressive thrombosis could be followed by a serial angiograms over a period of four hours while a current of $2 \mathrm{ma}$ and 2 to $3 \mathrm{v}$ was applied to the wire. At the conclusion of the procedure, a Selverstone clamp applied to the carotid artery in the neck was unfortunately closed and this resulted in occlusion of the carotid the next day. No paralytic sequelae resulted.

A more fortunate case, a 70 year old woman, was treated by merely introducing a copper wire into the cavernous sinus through the right superior orbital vein. No current was applied because of the woman's age. Two months later angiography showed that the fistula was closed and a recheck angiogram more than one year later gave the same result. The carotid artery is patent and the woman has no neurological defect. The severe pain which she had in her right eye before operation has never reappeared.

Technical details of this procedure will be outlined.

\section{Forelimb Control After Lesions in the Dorsal Funiculi of Squirrel Monkeys}

Charles Beck, Edmonton, Alberta

Electrolytic lesions were made under stereotaxic guidance in the dorsal funiculi of squirrel monkeys. Sham-operated controls were compared to the lesioned animals in their preoperative and postoperative performance on four forelimb tasks: retrieval of bait from behind a transparent barrier, bait retrieval from behind an opaque barrier, bait retrieval from a box containing bait size inedible objects and catching a falling bait. The experimental animals were impaired only on the latter task. The remarkable performance of the animals with lesions in the first three tasks was not expected. The results suggest that the contribution of information conveyed in the dorsal funiculi of the squirrel monkey is apparent only when very rapid corrective adjustments in the programming of movements are required.

\section{Neurophysiological Changes Following Spinal Lesions in Man}

P. Ashby and M. Verrier, Toronto, Ontario

Transmission in 3 spinal reflex pathways has been measured in patients with acute complete spinal lesions and in patients with longstanding complete spinal lesions. Profound changes in presynaptic inhibition and in transmission in a Ia polysynaptic pathway to motoneurones are observed. A hypothesis is proposed to provide a neurophysiological explanation for the evolution of the clinical features that follow a complete spinal lesion in man.

Transmission in these reflex pathways in patients with severe, but incomplete, acute spinal lesions show significant differences from those with complete lesions. These differences may depend upon the integrity of long tracts that cannot be tested by clinical examination.

\section{The Brain Stem Electroencephalogram:}

Clinical and Experimental Observations of Click Evoked Eighth Nerve and Brain Stem Responses in Human and Animal Subjects Henry Berry, Toronto, Ontario

Repetitive click stimuli can be used to evoke electrical responses from the lower portion of the auditory pathway (electrocochleogram) and this has been of considerable interest to the audiologist. The first ten milliseconds of activity, after the stimulus, contains the electrical responses of the auditory nerve and brain stem connections; the recording can be regarded as a form of brain stem EEG.

A surface method is used along with a signal averaging system and a general purpose computer. Our experience in the normal subject confirms that five waves (N1-N5) can be recorded with differing stimulus parameters. There is evidence that $\mathrm{N} 1$ represents the auditory nerve action potential and that the subsequent responses represent brain stem neural activity. Similar activity can be recorded in the cat and published observations suggest that waves N2 and N3 are derived from the cochlear nucleus and superior olivary complex respectively, and that N4 and $\mathrm{N} 5$ are generated by the inferior colliculus. Our studies of the effect of stereotactically placed brain stem lesions in the cat suggest that the origin of these potentials is a more complex one.

The wave forms are altered by lesions of the auditory nerve and brain stem and our experience with this method in various clinical conditions, and as a non-invasive assessment of brain stem function, is presented.

Tonic and Spasmodic Torticollis in Monkeys

L. LaRochelle, M. Filion and L. J. Poirier, Quebec, Quebec

Tonic torticollis has frequently been encountered in our laboratory following unilateral brain stem lesions at the level of the pontomesencephalic tegmentum in monkeys and cats. It is characterized by an involuntary permanent flexion or rotation of the head toward the side opposite to the lesion. It is slightly exaggerated by external stimuli.

Recently, a monkey, with a bilateral upper midbrain tegmental lesion, showed the following signs: hypokinesia, rigidity with the cog-wheel phenomenon in the four limbs and a postural tremor in the inferior left limb which was moreover slightly paretic. Following injection of alpha-methyl-para-tyrosine (AMT) (100mg/kg, i.d., for two days, i.p.), a tyrosine-hydroxylase inhibitor, this animal became completely akinetic and a spasmodic toritcollis did appear. As soon as the animal was left unstimulated its head spontaneously turned and kept rotated toward the left side. This phenomenon was completely abolished together with akinesia following L-DOPA $(30 \mathrm{mg} / \mathrm{kg}$, i.p.) or dopamine agonists like apomorphine $(0.2 \mathrm{mg} / \mathrm{kg}$, i.m.). These drugs however did not counteract tremor nor rigidity in this animal.

Histopathological studies suggest that the interruption of some components of the central tegmental tract is an essential feature underlying the appearance of the torticollis. A short film demonstrating the spasmodic torticollis will be shown.

\section{Narcotic Interactions with Caudate Neurons}

G.G. Yarbrough and A. T. Arbus, Saskatoon, Saskatchewan

There is a large body of behavioural and biochemical evidence suggesting that some narcotic effects, principally those on motor activity, are mediated through alterations in striatal mechanisıns. We, therefore, have investigated the effects of morphine, administered iontophoretically and systematically, on rat caudate neuronal responses to the putative transmitter substances dopamine (DA), serotonin (5HT) and gamma amino butyric acid (GABA). In methoxyflurane anaesthetized animals, iontophoretically applied morphine or methadone (5-100nA, 0.5-5 min.) consistently depressed glutamate excitability but failed to attenuate neuronal responses to either DA or GABA. However, i.v. injections of low doses of morphine were observed to antagonize the effects of iontophoretically applied DA and GABA on caudate neurons. The effects of constant doses of DA (35nA), 5HT (40nA) and GABA $(35 \mathrm{nA})$ on glutamate-induced neuronal excitability were examined in rats receiving (1) a single i.p. injection of morphine $(15 \mathrm{mg} / \mathrm{kg})(2)$ morphine $(15 \mathrm{mg} / \mathrm{kg})$ plus naloxone $(10 \mathrm{mg} / \mathrm{kg})$ (3) chronic injections of increasing doses of morphine for 11-22 days, and (4) chronic saline injections. As shown in the table, the proportions of cells inhibited by all three substances were reduced in the acutely morphinized animals and tolerance to this effect developed in the chronic morphine rats.

\begin{tabular}{lccc}
\multicolumn{4}{c}{ CAUDATE CELLS INHIBITED } \\
& DA & 5HT & GABA \\
\hline Morphine & $13 / 77(17 \%)$ & $16 / 75(21 \%)$ & $24 / 74(32 \%)$ \\
Morphine and & & & \\
$\quad$ Naloxone & $18 / 40(45 \%)$ & $19 / 39(48 \%)$ & $27 / 39(69 \%)$ \\
Chronic Morphine & $21 / 51(41 \%)$ & $21 / 41(52 \%)$ & $31 / 43(72 \%)$ \\
Chronic Saline & $17 / 39(44 \%)$ & $22 / 39(56 \%)$ & $26 / 37(70 \%)$
\end{tabular}

These data indicate that (1) while effects of morphine on caudate neurons are probably not due to a direct blockade of aminergic or amino acid receptors, the efficacy of dopaminergic, serotonergic, and gabaminergic transmission may be impaired and (2) tolerance to this acute narcotic effect, which is demonstrable at the level of individual caudate neurons, is not likely to involve a development of post-synaptic supersensitivity. 


\section{Monoamines Effects on the Depression Frequency Facilitation and Post-Tetanic Potentiation at a Cholinergic Synapse in Aplysia Californica \\ Jacques P. Tremblay, Quebec, Quebec}

Paul B. J. Woodson and Werner T. Schlapfer, San Diego, California

We have studied the action of several monoamines (specifically dopamine and serotonin) upon a monosynaptic, unitary and cholinergic EPSP recorded in the cell R15 in the abdominal ganglion of Aplysia californica.

Trains of 100 stimuli at $1 / \mathrm{sec}$, followed by test pulses ranging from 5 to $60 \mathrm{sec}$ were given every $30 \mathrm{~min}$. At this frequency of stimulation, the first few EPSP's decrease in size (depression) but this is followed by an increase to a sustained facilitated plateau (frequency facilitation). The train of stimulation is followed by a period during which an isolated stimulus produce an EPSP larger than at the facilitated plateau (posttetanic potentiation). This PTP reached a maximum $30 \mathrm{sec}$ after the end of the train and lasted for 10-30 mins.

Amines at concentrations ranging from $5 \times 10^{-6} \mathrm{M}$. to $5 \times 10^{-4} \mathrm{M}$. were then perfused. Both dopamine and serotonin produce the following ef fects: reduction of the size of the first few EPSP and the train, reduction or suppression of the depression, increase of the relative amount of frequency facilitation (100th EPSP/1st EPSP) and reduction of the PTP in size and duration.

The effect of serotonin and dopamine were completely blocked by complete replacement of $\mathrm{Na}+$ by $\mathrm{Li}+$ in the perfusate, previous to the addition of the amine. The effects of dopamine but not of serotonin were reduced by haloperidol and propranolol. These effects of the amines are considered presynaptic since dopamine and serotonin have opposite postsynaptic effects on the resting potential and the membrane resistance of $\mathrm{R} 15$, and antagonists of their postsynaptic action (BOL-148, ergometrine) did not antagonize their effects on the depression, facilitation and PTP.

\section{Cerebral Distribution of Amphetamine and p-Hydroxyamphetamine in the Rat}

T. J. Danielson and A. A. Boulton, Saskatoon, Saskatchewan

Amphetamine and $p$-hydroxyamphetamine levels were determined in whole brain and in seven discrete brain regions of the rat after intraperitoneal injection of low doses of D-amphetamine sulfate. Analysis of these amines after isolation, derivatisation (dimethylaminonaphthalene-5-sulfonyl-(Dansyl) amides) and chromatographic separation was accomplished using the direct insertion probe mass spectrometric Integrated Ion Current technique.

Results of the whole brain study indicated that amphetamine and $p$-hydroxyamphetamine rapidly entered the brain but were eliminated at different rates. $p$-Hydroxyamphetamine levels were reduced at a rats much slower than those of amphetamine. Regionally, amphetamine became distributed in a nearly homogeneous fashion although statistically significant differences were detected between some of the regions. The highest concentrates were found in the hippocampus and the lowest in the cerebellum. $p$-Hydroxyamphetamine, on the other hand, became heterogeneously distributed. Of the seven regions, the caudate nucleus contained the highest concentration. These regional distributions of amphetamine and $p$-hydroxyamphetamine were found to parallel closely the distribution of their lower homologues, phenylethylamine and $p$-tyramine respectively, in the brains of rats after treatment with mono-amine oxidase inhibitors.

\section{NEUROSURGICAL GUEST SPEAKER}

\section{Dr. I. S. Cooper}

Cerebellar Implantation and Chronic Cerebellar Stimulation for Epilepsy

\section{Alternate Day Prednisone Treatment of Myasthenia Gravis}

\section{John G. Humphrey, Toronto, Ontario}

Alternate day single dose prednisone has been given to 34 patients with myasthenia gravis for 6 months to $4 \frac{1}{2}$ years. The patients were from 16 to 80 years and include 11 men and 23 women. 28 had undergone prior thymectomy $-8(29 \%)$ had a thymoma, $15(54 \%)$ had hyperplasia and $5(17 \%)$ had atrophic thymic tissue. Clinically 2 patients had ocular myasthenia (group 1), 4 had mild generalized myasthenia (group 2), 17 had moderate to severe general myasthenia (group 3) and 11 had chronic moderate to severe myasthenia (group 4). 23 of the 34 had received one or more courses of 1000 units of ACTH prior to prednisone. Single dose (alternate day) prednisone was begun immediately after ACTH in 23 patients and was gradually increased in 11 to maintenance levels of $30-100 \mathrm{mg}$ (mean $-60 \mathrm{mg}$ ). A number of patients required single dose daily prednisone initially because of wide swings in their myasthenic weakness and 3 patients continue to require daily prednisone.

$\begin{array}{llllll}\text { Results } & \text { Groups } & 1 & 2 & \frac{3}{6} & \frac{4}{4} \\ \text { Improved } & & & & 4 & 2 \\ \text { Improved + Relapse } & & & & 1 & 5 \\ \text { Not improved } & & & & 1\end{array}$

16 moderate or severe patients were either in remission or much improved while 6 improved but relapsed either spontaneously or as the prednisone was reduced. 6 patients showed no response after 3-12 months of prednisone - one dying of an undetected thymoma and 5 having chronic myasthenic weakness for 4 to 9 years prior to prednisone.

Alternate day prednisone is useful in ocular and mild generalized myasthenia gravis with or without thymectomy. In moderate or severe patients $58 \%$ were improved or in full remission and $20 \%$ had no benefit. The role of thymic pathology, trans cervical thymectomy and duration of myasthenia gravis will be further discussed in relationship to the use of alternate day prednisone.

\section{'Double Crush' Entrapment Neuropathies}

A. R. M. Upton and A. J. McComas, Hamilton, Ontario

Neurophysiological studies, particularly the use of motor unit counting techniques in more than 800 patients with clinical symptoms and signs of peripheral entrapment neuropathies have caused us to suggest that apparently localized peripheral nerve entrapments may arise as a result of serial constraints of axoplasmic flow.

Nerve root and plexus lesions may predispose to the development of carpal tunnel, cubital tunnel, peroneal, radial or anterior interosseus nerve syndromes while metabolic disorders (e.g. renal, diabetic, B12 or nutritional) and even an upper motoneurone lesion may act as additional 'unmasking' factors. Since 1958 proximal symptoms in the carpal tunnel syndrome have been attributed to referred pain although such symptoms are often aggravated by proximal factors and did not occur in 48 consecutive cases of localized peripheral nerve trauma involving median, ulnar, radial or peroneal nerves. Denervation changes outside median nerve territory were noted in $60 \%$ of our patients with carpal tunnel syndrome and proximal symptoms. There was a significant difference in the neurophysiological results between patients with proximal symptoms and those without. Serial electrophysiological studies on patients after cervical nerve root trauma, Cloward procedures and brachial plexus injuries have revealed the progressive development of carpal tunnel or cubital tunnel syndromes.

The clinical significance of proximal symptoms such as scleratomal pain or brachial plexus tenderness in patients with peripheral 'entrapment' neuropathies will be discussed in terms of conservative and surgical treatment.

\section{The Location of Conduction Abnormalities in Human Entrapment Neuropathies}

M. W. Jones, W. F. Brown and G. G. Ferguson, London, Ontario

The purpose of this investigation was to better understand the mechanisms that produce entrapment neuropathies. It was prompted, in part by the failure of many 'surgical corrections' of ulnar nerve entrapments at the elbow judged by critical review of the local experience and most published reports. The methods have included detailed pre- and post-operative electrophysiological and clinical appraisals. In addition, at the time of surgical exploration of the affected nerve, the conduction velocity and degree of conduction block were measured at $0.5-1.0 \mathrm{~cm}$ intervals along the exposed nerve, including, in the case of the ulnar nerve, the cubital tunnel.

Observations included:

(1) The major increase in conduction time, often combined with conduction block, was located in a short $(0.5-2 \mathrm{~cm})$ length of the nerve. 
(2) In the ulnar nerve elbow entrapments, the conduction abnormalities were not located in the cubital tunnel, but over a segment $1 \mathrm{~cm}$ proximal and distal to the tip of the olecrannon.

(3) In the median nerve, carpal tunnel entrapments, conduction block was common, but the location of the major conduction abnormalities, even if limited to a short segment of the nerve $(0.5-1.0 \mathrm{~cm})$, could vary, from patient to patient, along the length of the carpal tunnel.

(4) The location of the most important conduction abnormalities, particularly in the ulnar nerve, could not be predicted by external inspection of the nerve alone.

\section{Hereditary Brachial Neuropathy}

Henry G. Dunn, Vancouver, British Columbia

Hereditary brachial neuropathy is characterized by recurrent attacks of pain in one or both shoulders and arms, followed by weakness and wasting of affected muscles. In the acute stage some sensory loss and autonomic disturbance may also be observed. The condition differs somewhat from sporadic neuralgic amyotrophy, since (1) attacks usually begin in childhood, (2) both sexes are affected about equally, and women may have attacks precipitated by pregnancy, (3) the patient often has hypotelorism and may show other congenital defects, e.g. small stature, cleft palate, ptosis and syndactyly, and (4) recurrences are more common and recovery is more often incomplete.

Three affected children, aged $4 \frac{1}{2}$ to 8 years, in different families were studied with electrodiagnostic methods. Conduction velocity in motor fibers of the median, ulnar and lateral popliteal nerves was normal. The amplitude of the evoked compound action potentials was often low in affected muscles. The sensory action potential in median and radial nerves was of abnormally low amplitude in acutely involved arms. Electromyography showed fibrillation potentials in the acutely weak muscle group in only one child, but evidence of partial denervation was present in all and extended to leg muscles in two of the three children, thus demonstrating the widespread distribution of the disorder.

\section{Dominantly Inherited Hypertrophic Peripheral Neuropathy \\ Quais Ghanem, Satish Mongia, Edward A. Atack and David N. Preston, Ottawa, Ontario}

This paper presents the results of an investigation of a family of $\mathbf{3 0}$ members, spread out over four generations. 17 of these were found by clinical, electrophysiological and histological investigation to have a diffuse hypertrophic peripheral neuropathy with a dominant inheritance.

There was no tremor detected nor any abnormal eye signs. Areflexia was common to all affected members, and this proved to be a reliable sign of involvement. Pes cavus and palpable nerve thickening was present in more than half the affected members. Of interest was the fact that three affected members also had trigeminal neuralgia, and the propositus had marked tongue fasciculation. The majority of affected members had, in addition to the symmetrical distal weakness, a symmetrical proximal weakness involving the hip and shoulder girdles. It was also found that the proximal ulnar nerve conduction velocities were slightly but consistently more severely reduced than the distal ulnar velocities.

This family is thus being presented as having dominantly inherited hypertrophic peripheral neuropathy. Three affected members had trigeminal neuralgia: an unusual occurrence in peripheral neuropathy. To our knowledge this family is unique when compared to other reports of familial hypertrophic peripheral neuropathy in the literature in that:

1. There is an unusual degree of proximal weakness.

2. This is combined with slowing of conduction velocities in proximal nerve segments.

3. The inheritance is dominant.

\section{Familial Collagen Vascular Disease with} Neurological Involvement

I. E. Leppik, E. Andermann, F. Andermann, S. Carpenter, A. Eisen and G. Karpati, Montreal, Quebec

Collagen vascular disease with spastic paraplegia in an individual is unusual, familial occurrence of this is unique. We have ascertained five generations of a large, highly consanguineous kindred from St. Thérèse de Gaspé of Acadian descent. 13 individuals in 4 sibships from the last two generations exhibited a spectrum of clinical manifestations ranging from inflammatory myopathy to spastic quadriplegia with mental retardation. The propositus, A.D., developed symptoms of spastic paraplegia at age $2 \frac{1}{2}$, had subarachnoid hemorrhage from an aneurysm at age 12 , and at 14 had positive LE preps and inflammatory myopathy seen in his muscle biopsy. His brother developed weakness at age 12, and muscle biopsy confirmed the diagnosis of childhood dermatomyositis. His sister developed juvenile arthritis at age 3, had positive ANA and RA factors, later had pericarditis. Her biopsy showed undulating tubules in muscle endothelial cells, characteristic of inflammatory myopathy. Five other siblings have no definite abnormalities, but the father has discoid lupus confirmed by biopsy. The father's sister has nine children: one with spastic paraplegia, 2 with severe mental retardation and spastic quadriplegia. Two second degree cousins of A.D. have spasticity with mental retardation without collagen vascular disease. Although familial occurrence of collagen vascular disease has been occasionally reported in SLE, this family is unique in the number of affected individuals and preponderance of muscle involvement. The apparently random combination of manifestations in this highly inbred kindred would suggest that at least 2 autosomal recessive traits, that for collagen vascular disease and spastic paraplegia, are segregating independently. However, the possibility of a single mutant gene with pleiotrophic effects cannot be excluded.

\section{Carotid Arteritis and Panhypopituitarism}

R. S. McPhedran, G. Moddel and S. Rife, Toronto, Ontario

A few cases are described in the world literature relating Cranial Arteritis to the Clinical findings of a non-surgical cause of panhypopituitarism with bitemporal field defects.

The mechanism of this process has been clarified by the studies of Bergland and Ray by defining that the decussating fibers in the optic chiasm and the adenohypophysis receive arterial perfusion from inferior branches of the Internal Carotid, Posterior Communicating and Posterior Cerebral Arteries. Stretching of these vessels from an expanding pituitary neoplasm accounts for the resolution of the bitemporal field defects after resection. Pathological demonstration by Crompton of involvement of 'these branches in a case of Cranial Arteritis is documented.

A further case of a forty-six year old male has been studied for eighteen months, who presented with a nine month history of progressing pituitary insufficiency, orbital bruits, and bitemporal field defects. Endocrine studies confirmed the presence of pituitary insufficiency and carotid arteriography showed an unusual symmetrical Siphon Stenosis of the Internal Carotid Arteries. Other radiological procedures showed no evidence of a pituitary neoplasm. The Carotic Siphon Stenosis evolved in one month to a symmetrical retrograde thrombosis of these structures.

A presumptive diagnosis of Arteritis was supported by an elevated E.S.R. and Beta 1C; transient carotid and subclavian bruits, transient pulse pressure discrepancies in the arms, the reversal of overt E.K.G. abnormalities after steroid therapy and the acknowledged rarity of bitemporal field defects in arteriosclerotic disease. Treatment by endocrine replacement, high dose steroids and anticoagulation have produced a resolution of the field defects and a return of the patient to an active life pattern.

Ischemia from Arteritis is proposed as a reversible cause of panhypopituitarism and bitemporal field defects.

\section{Retrospective Study on Carotid Surgery} (Preliminary Report)

Jean-Pierre Bouchard, Denis Simard, Michel-N. Drolet, Jacqueline Fabia, Paul Roy and Jacques Cote, Quebec, Quebec

\section{Recurrent Atheroma at the site of Previous Carotid Endarterectomy}

B. N. French and N. B. R. Rewcastle, Toronto, Ontario

Nineteen carotid arteries obtained at postmortem examination from patients who underwent carotid endarterectomy from 1 hour to 11 years previously were studied. Four arteries demonstrated recurrent atheromatous disease at the original endarterectomy site. Two cases examined 5 and 11 years after endarterectomy had asymptomatic recur- 
rent atheroma of minor degree. Neither patient suffered hypertension, diabetes or hyperlipidemia. Two cases of recurrent atheroma were symptomatic and required repeat endarterectomy. In each case postoperative angiography had demonstrated a patent endarterectomy site after first endarterectomy. One patient had diabetes, hypertension and hypercholesterolemia and developed recurrent symptomatic atheroma 16 months after first endarterectomy. A second patient suffered generalized peripheral vascular and coronary artery disease and developed recurrent symptomatic carotid atheromatous occlusion 11 years after first endarterectomy.

Our pathological observations and reported experimental hypercholesterolemic animal models showing atheroma in regenerating in tima indicate a group of patients who are subject to recurrent symptomatic atheromatous disease at the original endarterectomy site. It is the surgeon's responsibility to ensure that the risk factors of hypertension, diabetes and hyperlipidemia are aggressively managed after carotid endarterectomy.

\section{The Investigation of Cerebral Perfusion Using Intra-Arterial Injection of Isotopically Labelled Albumin Macroaggregates \\ J. M. Allcock and M. Chamberlain, London, Ontario}

Macroaggregates of human serum albumin of mean size approximately 20 microns have been injected into the carotid and/or vertebra arteries during the course of cerebral contrast angiography. The biodegradable particles mix with arterial blood and become impacted temporarily in capillaries in the territory of perfusion of the artery. A scan of the distribution of the radio-label then represents the extent of the territory perfused. If the scan data is subject to computer analysis the relative distribution of blood flow within the territory may be measured. As in other anatomical locations, perfusion scanning at the capillary level may add complementary information to that obtained concerning larger vessels by contrast angiography.

The method has proved safe with no observed morbidity. Double isotope studies using ${ }^{99} \mathrm{mTc}$ and ${ }^{131} 1$ labels have allowed the delineation of territories of the different main cerebral arteries together with the extent of cross-over from left to right and collateral and double blood supply. Shunting in vascular malformations and tumors has been evident as 'cold' areas. The method promises to be of value in the investigation of transient ischemic attacks and arterial occlusions and particularly in pre and post-operative assessment of patients submitted to external/internal carotid shunt procedures. It may also be used to show perfusion abnormalities in patients who develop arterial spasm following subarachnoid hemorrhage.

\section{The Clinical Uselessness of Photic Stimulation in EEG Localization}

$$
\text { W. T. Blume, London, Ontario }
$$

Since the introduction of photic stimulation to clinical EEG, there have been remarkably few studies relative to the clinical value of the photic driving response, yet this response is duly sought and reported upon routinely in most EEG laboratories.

Among 1900 patients, 181 had initial recordings with asymmetrical driving response (defined as an inter-occipital voltage difference exceeding $33 \%$ ) at one or more flash rates. Those were matched with an equal number of patients with a symmetrical driving response. Although 67 of $181(37 \%)$ patients with asymmetrical driving had localising or lateralising supratentorial lesions as compared to $26(14 \%)$ with symmetrical driving, only 7 of the 67 failed to have other lateralising or localising features on their recordings. This number is exceeded by the 80 patients with non-lateralising resting records, asymmetrical driving response and no hemispheric lesion.

Of the 67 , highest driving was contralateral to the lesion in 31 cases, ipsilateral in 22 , and variable at different frequencies in 14 . The existence of an electrographically acute lesion, defined as the presence of excess delta activity for age, did not significantly affect laterality.

\section{Is There a Role for Vitamin E Therapy in Epilepsy in Man?}

A. O. Ogunmekan, A. K. Ghoshal and J. A. Lowden, Toronto, Ontario

Rats exposed to $100 \%$ oxygen are susceptible to seizures. Jerret et al. (1973) found that these seizures could be prevented by prior administration of vitamin $E$.
If this were also true in man it would revolutionize the current management of epileptics who are particularly refractory to therapy.

There have been over 2,000 publications on the clinical use of vitamin $E$ for almost every medical disorder. Many of these have little in common with the experimentally-induced manifestations of vitamin $\mathrm{E}$ deficiency. To name a few: skin problems, muscle diseases, sterility in man, habitual abortion, physical vigour and well being, intermittent claudication.

This study developed following the chance observation of a low plasma level of vitamin $E$ in a mentally retarded child with seizures. Previous reports indicate that young and adolescent children have a normal plasma level range of $1000-1200 \mu \mathrm{g} / \mathrm{dl}$ with a slight tendency for values to increase with age. Low plasma levels can occur in diarrhoea, malabsorptive states, liver diseases and during iron therapy. Vitamin $\mathrm{E}$ content in the brain is minimal because of blood brain barrier.

We assayed plasma vitamin $E$ in 41 patients from the surgical wards, of the Hospital for Sick Children. They had been admitted for minor surgical procedures. The children's ages ranged from 2 to 18 years. They were apparently normal children with no medical problems and on no medication. Their vitamin $\mathrm{E}$ levels fell into normal distribution $813 \pm 14 \mu \mathrm{g} / \mathrm{dl}$ mean $t(\mathrm{SD})$. Vitamin $E$ levels were also assayed in 29 patients with seizure disorders who were on anticonvulsant drugs either singly or in combination (phenobarbitone, diphenylhydantoin and primidone). Their average plasma levels $(620 \pm 30 \mu \mathrm{g} / \mathrm{dl})$ were lower $(\mathrm{p}<0.01)$ than those in the control group.

There was no positive correlation between vitamin $E$ levels and blood levels of anticonvulsants, length of therapy, presence of mental retardation or doubtful seizure control. In some epileptic patients low levels of vitamin $\mathrm{E}$ may contribute to poor seizure control but the association is not a general phenomenon.

Further work to prove or disprove this hypothesis is obviously required.

Gamma-Hydroxy-Butyrate in the Treatment of Compound Narcolepsy: A Preliminary Report

R. Broughton, Ottawa, Ontario

M. Mamelak, Toronto, Ontario

Gamma-hydroxy-butyrate (GHB), a component of normal GABA metabolism, has been used to attempt to normalize nocturnal sleep in 4 patients (all female, mean age $\mathbf{3 8 . 2}$ years) suffering from chronic narcolepsy-cataplexy and withdrawn from previous treatment. The medication* comes as a $150 / \mathrm{ml}$ solution and has been given in initial doses of $15 \mathrm{ml}(2.25 \mathrm{gm}) \mathrm{hs}$., followed by $10 \mathrm{ml}(1.5 \mathrm{gm})$ with each nocturnal awakening, if over 3 hours from the previous dose. (Most of the compound is metabolized in three hours.) The maximum nightly dose has been $5.25 \mathrm{gm}$.

GHB led to increased nocturnal sleep with fewer awakenings, an increase in nocturnal REM sleep and stage $3+4$ (slow wave) towards normal levels and, over 2-4 days, to total disappearance of daytime sleep and cataplexy. Patients also felt somewhat less somnolent during the daytime, became less depressed and were emotionally more stable. In one patient the dosage was substantially reduced (to $2.25 \mathrm{gm} / \mathrm{night}$ ) after several days and the therapeutic effect sustained. The duration of the treatment period has been $2-12$ weeks. Cessation of medication has led to rapid ( $1-3$ day) reversal to previous symptomatology. No serious side effects have been encountered. It is tentatively concluded (1) that GHB appears to be a useful compound in the control of the symptoms of narcolepsy, and (2) that the daytime symptoms are secondary to the nocturnal sleep disturbance. The lowered vigilence levels, however, appear to be relatively refractory to GHB.

\section{Optimal Combination Therapy with Dilantin and Phenobarbital}

\section{E. Leppik and A. L. Sherwin, Montreal, Quebec}

The optimal ratio of diphenylhydantoin (DPH) to phenobarbital (PB) in the treatment of epilepsy is still unestablished. Male rats (83) were given DPH, PB or a combination subcutaneously and tested for abolition of the full hindlimb tonic extensor component of maximal electroschock seizures (MES) 2 hrs later. EDso values were determined to be 29.3 $\mathrm{mg} / \mathrm{kg}$ for DPH and $5.3 \mathrm{mg} / \mathrm{kg}$ for PB. These values were used to calculate combinations of DPH and PB, and doses giving groups between zero and $100 \%$ protection were used. Animals were sacrificed immediately after MES and drug levels determined in plasma and brain by gas-liquid 
chromatography. Using a single drug there was a significant difference between mean plasma drug levels of protected and unprotected rats: DPH of protected $5.0 \pm 1.0 \mu \mathrm{g} / \mathrm{ml}$, of unprotected $1.9 \pm 0.3(p<0.05)$; PB of protected $6.1 \pm \overline{11.6}$, of unprotected $3.3 \pm 0.3(\mathrm{p}<\mathrm{j} .01$ ). In combination treatment the mean total (DPH \& PB) plasma levels were $5.3+0.5$ for protected and $6.5 \pm 0.6$ for unprotected, and mean total brain Tevels were $4.0 \pm 0.4 \mu \mathrm{g} / \mathrm{gm}$ and $5.0 \pm 0.5$ respectively. The difference in mean total drugs was not significant, but the PB:DPH were most effective. In reviewing 50 patients on combination therapy, the average PB` level was 22.9 and DPH level 11.9 and thus it appears that experimental data corroborate clinical experience.

\section{Response of Generalized Penicillin Epilepsy in the Cat} to Ethosuximide (Zarontin)

Alan Guberman, Allan Sherwin and Pierre Gloor, Montreal, Quebec

Generalized epileptic activity induced in the cat following the parenteral administration of large doses of penicillin closely resembles, clinically and electrographically, human myoclonic petit mal epilepsy. Ethosuximide and diphenylhydantoin (DPH, Dilantin), were compared in 11 cats for their effectiveness in reducing the number of epileptic bursts recorded from chronically implanted diploic screw electrodes following intramuscular penicillin. The anticonvulsants were administered for 3-5 days prior to testing and 'steady-state' plasma levels determined during each experiment by gas chromatography.

The penicillin EEG epileptic bursts were reduced by $67.4 \% \pm 10.6 \%$ (S.D., $\mathrm{n}=8$ ) following administration of ethosuximide with plasma levels over $60, \mu \mathrm{g} / \mathrm{ml}$ (mean, $135, \mu \mathrm{g} / \mathrm{ml}$ ). A significant linear correlation between plasma level and reduction in epileptic activity was observed $(\mathrm{p} /<$ 0.01 ). In contrast, at plasma levels over $10 \mu \mathrm{g} / \mathrm{ml}$ (mean, $20.7 \mu \mathrm{g} / \mathrm{ml}$ ) DPH produced $45.4 \% \pm 16.0 \%(S . D ., n=10)$ reduction in epileptic activity. There was no correlation between plasma DPH levels and the reduction of seizure activity. In four cats both drugs were given successively. All responded well to ethosuximide, while only two were affected by DPH. The good response to ethosuximide, but only slight response to $\mathrm{DPH}$, is in keeping with clinical experience and further substantiates the value of this model of human petit mal epilepsy.

\section{DISTINGUISHED GUEST SPEAKER OF THE CONGRESS}

$$
\text { Dr. C. G. Phillips }
$$

"Laying the Ghost of Muscles Versus Movements"

\section{Symposium on Clinical and Basic Research in Neuroscience "Mechanisms in Motor Control" \\ Chairman: Dr. V. B. Brooks}

Clinical Problems of Motor Systems Disease, J. C. Richardson, Toronto.

Central Mechanisms of Tremor in Some Feline and Primate Models, Y. Lamarre, Montreal.

New Approaches for Studying Normal and Abnormal Motor Control, R. B. Stein, Edmonton.

The Effects of Motor Cortical Stimulation on the Excitability of Spinal Motoneurons in Man, H. S. Milner-Brown, J. P. Girvin, W. F. Brown, London

\section{Chairman: Dr. R. G. Lee}

Physiopathology of Experimental Parkinsonism in the Monkey, J. L.

Poirier, M. Filion, L. Larochelle, J. C. Péchadre, Quebec.

On the Role of the Cerebellum and Basal Ganglia in Initiation and Control of Movements, V. B. Brooks, J. Hore, J. Meyer-Lohman, Londoǹ.

Physiological Basis of Cerebellar Dysmetria, J. T. Murphy, H. C. Kwan, W. A. MacKay, Y. C. Wong, Toronto.

\section{Chairman: Dr. J. P. Girvin}

Motor Responses to Sudden Limb Displacements in Primates with Specific CNS Lesions and in Human Patients with Motor System Disorders, R. G. Lee, W. Tatton, Calgary don.

Why Transcortical Reflexes?, M. Wiesendanger, D. C. Rüegg, Lon-

Decorticate Spasticity: A Re-examination Using Quantitative Assessment in the Primate, R. R. Tasker, F. Gentili, K. Sogabee, Toronto.
Systems Versus Structural Localization of Motor Functions in Physiological and Clinical Studies, H. H. Jasper, Montreal.

\section{Changes in Peripheral Nerve After Radiofrequency Electrocoagulation}

J. Epps, A. J. Aguayo and G. M. Bray, Montreal, Quebec

Radiofrequency electrocoagulation is used for the surgical treatment of tix doloreaux and other neuralgias. Selective damage of small fibers is proposed as an explanation for the relief of pain and the relative sparing of other sensory modalities by this procedure.

The present report describes an experimental phase and electron microscopic investigation of changes that follow radiofrequency electrocoagulation of peripheral nerves.

In 12 adult mice the right sural nerve was exposed under general anesthesia and the tip of the $0.12 \mathrm{~mm}$ in diameter probe of a Radionics lesion-maker was placed over the perineurium. B mode electrocoagulation was carried out with currents of 50 or $100 \mathrm{~mA}$ applied for a total duration of $2.5,5,10,15,20$, or 25 seconds. The surgical incision was closed and animals were allowed to recover. All mice were sacrificed 6 days after injury by systemic glutaraldehyde perfusion and nerves were processed for phase and electron microscopy according to standard techniques. Nerve cross sections were examined at the level of injury and $3 \mathrm{~mm}$ above and below such level.

The severity of changes after radiofrequency coagulation was variable and consisted mainly of axonal degeneration. In all nerves the pathology involved both myelinated and unmyelinated nerve fibers and there was no selective fiber diameter loss. Thus, these findings suggest that the functional effects of radiofrequency coagulation may result from changes in sensory input patterns rather than selective small nerve fiber damage.

\section{Central Demyelination Versus Axonal Degeneration:} An Electrophysiological Study in Man

Andrew Eisen and Kenneth Laxer, Montreal, Quebec

The electromyographic muscle silent period (s- $x$ interval) was induced by nerve stimulation and recorded from the abductor pollicis brevis and gastrocnemius soleus muscles. The results obtained from 20 healthy volunteers were compared to a group of 23 patients with multiple sclerosis, and a group of 18 patients with motor neuron disease. The mean normal s- $x$ interval for the gastrocnemius soleus was $137.5 \pm 14.5$ msec., and for the abductor pollicis brevis was $122.9 \pm 12.0 \mathrm{msec}$. The mean difference between these values $(15.1 \pm 16.4 \mathrm{msec})$ gave a conduction velocity through the spinal cord from S1 to C8 of about 55 $\mathrm{m} / \mathrm{sec}$. In the multiple sclerosis group the mean $\mathrm{s}-\mathrm{x}$ value for the gastrocnemius soleus was $175.4^{\circ} \pm 46.5$, and the mean arm-leg difference was $53.4 \pm 41.6 \mathrm{msec}$. Both these values were significantly prolonged when compared to the control group ( $<<0.001$ ). In contrast, the mean $s-x$ intervals recorded from both muscles in the motor neuron disease group were normal. The silent period probably participates in recently described 'long loop reflexes'. Its delay in multiple sclerosis could therefore be due to a block in central conduction secondary to demyelination. This would not occur in motor neuron disease in which axonal degeneration is the primary pathology. The results of this study indicate that the established principles regarding conduction defects as they apply to demyelinating as opposed to axonal degenerating peripheral neuropathies, may hold equally true for the central nervous system. The methods employed are relatively simple and are considered a valuable means of determining central conductivity in man.

\section{A New Technique for Determining Conduction Velocity in the Proximal Segment of Motor Nerves}

D. King, Toronto, Ontario

A new technique has been developed that enables conduction velocity to be examined in the most proximal segments of a motor nerve.

Simultaneous proximal and distal stimulation of a motor nerve results in the occlusion of the distal antidromic and proximal orthodromic action potentials. The distal orthodromic $M$ wave and the proximally evoked $F$ wave remain and can then be recorded with surface electrodes over the muscle. The latency of the $F$ wave over the proximal segment can be calculated thus permitting the accurate determination of the motor conduction velocity from the spinal cord to the proximal site 
of stimulation, according to the equation $F$ Wave velocity in meters/sec. $=$ the distance from the stimulus point to the spine $x 2$ in $\mathrm{mm}$ divided by $\mathrm{F}$ latency $-\mathrm{M}$ latency -1 in $\mathrm{msec}$, the $1 \mathrm{msec}$ being introduced to allow for retrograde activation of the anterior horn cell.

Using this technique the conduction velocities in the proximal segment of a motor nerve in the upper limb have been determined in a group of normal subjects. These values will be contrasted with the findings in a group of patients with neurologic disease in which significant proximal pathology could be expected.

The technique has proven to be so simple that it may be easily utilized in routine clinical electrodiagnosis.

\section{Abnormal Conduction in Morphologically Normal Peripheral Nerves: An Electrophysiologic Light and Electron Microscope Experimental Study}

\section{Rasminsky, G. M. Bray and A. J. Aguayo, Montreal, Quebec}

The spinal roots of dystrophic mice show morphologic abnormalities but the more distal peripheral nerves appear normal (Bradley and Jenkinson, 1973). We have measured conduction velocities (CV) for the fastest fibers in the peripheral ventral tail nerve (VTN) of 11 to 13 week old dystrophic mice (129 ReJ-dy and 129 B6 FIJ-dy) and unaffected litter mates. Average $\mathrm{CV}$ in dystrophic animals were slower than in controls $(21+3 \mathrm{~m} / \mathrm{sec}$ and $32+4 \mathrm{~m} / \mathrm{sec}$ respectively - temp. $37 \pm 1^{\circ} \mathrm{C}$.). The ratio dystrophic $\mathrm{CV}=0.67 \pm 0.10$ for 17 litter mate control CV

pairs in which both animals were studied on the same day. Histologic fiber diameter measurements and myelin lamellae - axon circumference relationships were not significantly different in VTNs from dystrophics and controls. The ratio axon diameter was $0.78 \pm 0.06$ for fiber diameter

fibers in dystrophic mice and $0.79 \pm 0.03$ in control fibers. Axonal populations, internodal distances and morphology of nodes of Ranvier were also similar for dystrophic and control animals.

A possible explanation for the slow conduction velocity in fibers which appear normal in VTNs of dystrophic mice is an abnormality of active electrical properties of axonal membranes. Surface membrane abnormalities have also been demonstrated in skeletal muscle (Bray, 1973) and erythrocytes (Morse and Howland, 1973) of these dystrophic mice. Thus, the dystrophic mouse constitutes a model of a functional abnormality of nerve where morphologic changes, usually accepted as the explanation for slowing of conduction (segmental demyelination, paranodal retraction of myelin) cannot be demonstrated. Similar membrane abnormalities may be present in other neuropathies regardless of the presence or absence of demonstrable structural changes.

\section{An Experimental Evaluation of the Motor Unit Counting Technique \\ J. M. Peyronnard, Montreal, Quebec}

An electrophysiologic technique to determine the number of motor units in the extensor digitorum brevis (EDB) of man has been proposed by McComas et al, 1971. Findings by this technique have suggested there is a neurogenic cause for certain myopathies. However, conclusions based on counts from the EDB have been questioned because of marked variabilities in results from control subjects. Furthermore, a lack of experimental models has limited a full assessment of the technique and the significance of changes in motor unit counts remains unclear.

The present study represents a functional and morphologic correlation in the monkey where electrophysiologic estimates of motor unit counts in the EDB and histologic counts of alpha motor fibers innervating this muscle are compared.

In six adult monkeys (Macaca mulatta) counts on the right side were made after deafferentation by excision of lumbosacral dorsal root ganglia. On the intact left side, alpha motor axons were assumed to represent $50 \%$ of the total number of large myelinated fibers in the nerve to the EDB. In 5 animals the results from serial electrophysiologic counts of motor units showed a considerable variation for each animal but mean values were only less than $10 \%$ lower than histologic estimates of alpha motor fibers. However, no such correlation was found in one animal with a partial injury to motor roots innervating the extensor digitorum brevis.
These experimental findings suggest that in the normal, there is a close correlation of anatomic estimates of alpha motor fibers and electrophysiologic counts of motor units by these techniques. However, such a correlation may not be present in pathologic conditions.

\section{Familial Motor Neuron Disease}

T. J. Murray and Virgilio Sangalang, Halifax, Nova Scotia

In a review of cases of MND seen in Nova Scotia over a 10-year period, $6 \%$ had a positive family history of MND. The forms and variations of MND seen in these families will be discussed and compared to the non-familial cases.

Family No. 3 is of particular interest. A 47-year-old pharmacist died 14 months after the onset of progressive primary muscular atrophy involving mostly the bulbar musculature and upper limbs. 26 members of his family have died of a similar neurological disorder in four generations, making this the largest pedigree of familial MND described. At autopsy there was marked neurogenic atrophy of limb and bulbar musculature due to extensive motor neuron degeneration in the cord and brain stem. The degenerating neurons of the anterior grey horns contained intracytoplasmic hyaline inclusion bodies resembling Lewy bodies, similar to those described by Hirano and others. The inclusion bodies were most abundant in areas which were clinically in the earliest stages of involvement. There was no involvement of the pyramidal or spinocerebellar tracts or of the posterior columns, reported in some cases of familial MND. The study of this family has been important in better understanding this familial disorder and increasing the family's interest in genetic counselling for future generations.

\section{Cell Mediated Hypersensitivity in Peripheral Neuropathies}

D. W. Paty and H. K. Cousin, London, Ontario

Seventeen patients with polyneuropathy have been tested for evidence of cell mediated hypersensitivity $(\mathrm{CMH})$ to peripheral nerve antigens. The method is an indirect assay for human macrophage inhibition factor production using guinea pig macrophages as the indicator cell. Fifteen normals and 13 neurological controls with Central Nervous System disease have failed to show any significant inhibition by this method. $4 / 5$ patients with acute idiopathic polyneuropathy (Guillain-Barré) had marked sensitivity, 4 patients with chronic idiopathic neuropathy had intermediate levels of sensitivity, one out of two patients with carcinomatous neuropathy and one out of two with diabetic neuropathy also had moderate levels of sensitivity. Four patients with familial neuropathy or focal neuropathies demonstrated no sensitivity. The demonstration of $\mathrm{CMH}$ against peripheral nerve antigens seems to be almost universal in patients with acute idiopathic polyneuropathy, and of intermediate intensity in patients with chronic idiopathic polyneuropathy. This test might be considered as an adjunct to diagnosis of the Guillain-Barré syndrome. These results also suggest that many cases of chronic idiopathic polyneuropathy may have an autoimmune etiology, similar to that proposed for the Guillain-Barré syndrome.

\section{The Course of Uremic Neuropathy during Chronic Hemodialysis}

\section{F. Bolton, R. M. Lindsay and A. L. Linton, London, Ontario}

Sensory and motor nerve conduction studies have been proven to be a sensitive indicator of the degree of peripheral neuropathy in chronic renal failure. Such studies become abnormal prior to the development of clinical signs and show consistent improvement when normal renal function is restored by successful transplantation. As a result, they have been used to monitor the adequacy of chronic hemodialysis. However, their role in this regard has not been well documented, and the following investigation was therefore carried out.

Twenty-five patients were studied by nerve conduction studies at six-monthly intervals for two years, the patients having been on chronic hemodialysis for a mean of 17 months ( 1 to 71 months). Statistical analysis has shown no overall change in median motor and sensory, and peroneal motor, conduction velocities, although minor worsening or improvement occurred in a few individual cases. There was no clinical change in neuropathies which were initially mild or sub-clinical. A further analysis was done on 8 patients who were being dialysed at home three times weekly and 8 who were being dialysed in hospital 
twice weekly; each group was closely matched for age, sex and duration of hemodialysis. Both groups had mean values for conduction velocities which were at or below the lower limits of normal for all nerves tested. The patients on home dialysis had mean values which were slightly greater than patients on hospital dialysis, the difference being statistically significant for only median motor conduction velocity.

This study indicates that the major effect of chronic hemodialysis is a stabilization of uremic neuropathy, the home dialysis group faring slightly better than the hospitalized patients on less frequent dialysis. Reasons for the equivocal effect of chronic hemodialysis on the course of uremic neuropathy will be discussed.

The Effect of Spinal Cord Trauma on Regional Spinal Cord Blood Flow in Primates

Alan N. Sandler, Charles H. Tator and Virginia E. Edmonds, Toronto, Ontario

Considerable controversy exists regarding the effect of spinal cord trauma on spinal cord blood flow. Regional spinal cord blood flow was measured in primates using the $14 \mathrm{C}$ - antipyrine autoradiographic technique developed by Reivich et al. This technique requires a knowledge of the tissue tracer concentrations, the tissue-blood partition coefficient for the tracer and the arterial concentration of tracer during the 1 minute venous infusion.

The partition coefficient for 14C-antipyrine was determined in 9 rhesus monkeys in spinal cord white and grey matter. Thoracic cord blood flow was then measured in 4 normal monkeys and in 12 monkeys in whom the cord was injured by the circumferential extradural cuff technique with the cuff inflated to $400 \mathrm{~mm} \mathrm{Hg}$ for 5 minutes, a method known to produce major cord injury. In the injured monkeys, cord blood flow was measured in 3 monkeys at each time interval 15, 30, 60 and 120 minutes after injury with monitoring of blood gases, blood pressure and body temperature. Regional cord blood flow was determined from the optical density of cord autoradiographs using a scanning microscope photometer which allowed measurement of regional blood flow in $0.1 \mathrm{~mm}^{2}$ areas throughout entire $30 \mu$ thick cross sections of normal or traumatized cord. At this resolution there was clear differentiation between grey and white matter flow.

The partition coefficient for white matter was $0.79+0.09 \mathrm{SE}$ and for grey matter $1.13 \pm 0.22 \mathrm{SE}$. In normal cord, white and grey matter blood flow were $9.4+0.3 \mathrm{SE}$ and $50.5+2.5 \mathrm{SE} \mathrm{ml} / 100 \mathrm{~g} / \mathrm{min}$ respectively. At the early time intervals after trauma most of the animals showed a marked reduction in cord blood flow in both grey and white matter. Some animals showed both ischaemic and hyperaemic zones in white matter and grey matter illustrating the necessity of assessing blood flow changes after trauma with techniques capable of providing regional data.

These results support the concept that post-traumatic necrosis of the spinal cord observed in cords subjected to this type of injury may be due to post-traumatic ischaemia.

\section{Transient Ischemia and Infarction as a Delayed Sequel to Carotid and Vertebral Occlusion}

H. J. M. Barnett and A. Aldis, London, Ontario

\section{Clinical Aspects and Pathophysiology of Plateau Waves}

B. N. French and H. Schutz, Toronto, Ontario

Continuous ventricular pressure was recorded in 90 patients. Of these, 40 had demonstrated plateau waves of the Lundberg type A variety. In patients who were conscious distinct symptoms and signs were observed which correlated well with the occurrence of plateau waves. In comatose patients the correlation was less distinct but periodic cardio-pulmonary irregularities were observed. These periodic observations will be presented in detail.

Although much is known of the pathophysiology of plateau waves, the exact initiating factors remain obscure. Plateau waves occur at the steep part of the volume-pressure curve and signify impending decompensation. They are the result of an increase in cerebral blood flow volume due to vasomotor instability and a decrease in cerebral blood flow due to a decrease in cerebral perfusion. Plateau waves are usually aborted by hyperventilation as cerebral vasomotor tone is regained.
Plateau waves can be initiated by $\mathrm{CO}_{2}$ retention as well as by a number of non-specific external stimuli such as sound, pain and touch. This suggests the vasomotor instability, causing plateau waves, can be precipitated by metabolic and neurogenic influences. To test this hypothesis, the parasympathetic control was blocked with atropine in patients with plateau waves. Plateau waves and cardiac irregularities were abolished, but recurred when the atropine was metabolized.

\section{Appearance of Regional Changes in Metabolism \\ at a Critical Perfusion Pressure in Diffuse Cerebral Oligemia \\ Felix A. Durity, Vancouver, British Columbia}

The time course of tissue changes in adenosine triphosphate (ATP), phosphocreatine ( $\mathrm{PCr}$ ). Lactate (Lac), and pyridine nucleotide (DPNH) was studied following diffuse cerebral oligemia. Albino rabbits were lightly anaesthetized with intravenous Nembutal, paralyzed and ventilated to normal $\mathrm{PaCO}_{2}$. Graded oligemia was produced by raising intracranial pressure (ICP) via infusion of mock CSF into the cisterna magna.

At a cerebral perfusion pressure (CPP) of 40 torr for 20 minutes, animals $(n=3)$ maintained ATP and Lac values $(2.27$ millimoles $/ \mathrm{kg}$ wet weight and 1.82) close to control values (2.42 and $1.05, n=5$ and $\mathrm{p}<$ 0.05 ). $\mathrm{PCr}$ was slightly decreased (3.18 vs. 3.97$)$. EEG was altered.

At $C P P=30$ torr, the animals fell into two general groups. In group 1 $(\mathrm{n}=6)$, EEG was preserved although severely altered in 4 . After 5,10 and 20 minutes of the insult, ATP and PCr were still well maintained (2.27 and 3.68). However Lac was significantly elevated and in addition large regional cortical differences were noted. DPNH values were not raised. In Group $11(n=4)$, EEG was lowest in 1-6 minutes. ATP and $\mathrm{PCr}$ were generally less than $30 \%$ of control values, and 3-fold regional differences were evident. $\operatorname{Lac}(\overline{\mathrm{x}}=19.6)$ and DPNH were uniformly high.

At CPP $<20$ torr $(n=12)$, EEG became isoelectric in less than 1 minute. At 5 and 15 minutes of the insult ATP and PCr were virtually dissipated (0.18 and 0.10), and Lac was 14.9.

Thus in this model of oligemia a critical CPP around 30 torr has been demonstrated above which oligemia was not severe enough to affect ATP levels significantly. Below this level rapid severe depletion occurred. At CPP $=30$ torr, regional metabolic variations appeared, and normal ATP levels correlated well with preserved electrical activity and tissue DPNH values.

\section{Ergotamine Tartrate and Cerebral Blood Flow}

V. C. Hachinski, J. W. Norris, P. W. Cooper and J. G. Edmeads, Toronto, Ontario

Ergotamine tartrate is one of the commonest efficacious agents used in the treatment of migraine. Its therapeutic action is believed to be mediated through its effects on the cerebral and extracerebral circulation.

At the time of clinically indicated arteriography the regional cerebral blood flow (rCBF) was determined by the intracarotid ${ }^{133}$ Xenon method in 12 patients. 3 migraneurs (who developed a headache during the procedure) and 9 non-migraneurs had rCBF determinations at hypercapnia, normocapnia and 15 minutes after an intramuscular injection of $0.2-1.0 \mathrm{mg}$. of ergotamine tartrate. No significant change in the cerebral blood flow was observed after the injection of therapeutic doses of ergotamine tartrate.

It is concluded that the well-established therapeutic response to ergotamine tartrate is not mediated through effects on the cerebral circulation.

\section{The Cerebral Consequences of Minor Injury to the Vertebral Artery}

Michael Lee and S. J. Peerless, Vancouver, British Columbia

The literature abounds with references to carotid artery damage following head and neck trauma. Considering the frequency of severe cervical vertebral injuries and the infrequency of vertebral artery damage it seems that these arteries are well protected yet at the same time minor trauma to the neck including manipulation may cause damage to the vertebral artery with secondary occlusion and embolization to the brain.

A case of a 27 year old man with the sudden onset of a 'lateral medullary syndrome' occuring some four months after seemingly minor 
neck injury is discussed. Angiography demonstrated a significant narrowing of the ipsilateral vertebral artery at the $\mathrm{C} 1-\mathrm{C} 2$ level adjacent to boney injury.

An anatomical review of the vertebral artery will be presented emphasizing the possible sites of injury and reference will be made to manipulation and other forms of mild trauma with regards to the recognition and treatment of such lesions.

\section{Vertebral Basilar Occlusion in Rheumatoid Atlanto-Axial Subluxation}

M. W. Jones and J. C. E. Kaufmann, London, Ontario

The chronic 'myelopathy' associated with rheumatoid atlanto-axial subluxation has become well-defined since first reported in 1951. However, in spite of these reports, we are aware of only one previous pathologic report demonstrating the vertebral artery thrombosis leading to the patient's death.

Our patient was a 74 year old man with a 30-year history of rheumatoid arthritis, who in the nine months before death developed a progressive neurologic illness. There was vertigo on head flexion and standing; weakness and paraesthesias of his hands; and chronic continuous suboccipital head pain. Examination showed an orthostatic fall in blood pressure with vertiginous symptoms. Moderate global weakness with flexion contractures, depressed lower limb tendon reflexes and equivocal plantar reflexes were seen.

Radiological studies revealed marked atlanto-axial subluxation with instability and basilar invagination. Accordingly, skull tongs were inserted and traction on a Stryker frame was applied.

Unexpectedly during improvement, the patient was found comatose with Cheyne-Stokes respirations and decerebrate to painful stimuli. $\mathrm{He}$ remained in a 'coma vigile' state till death.

Pathological examination revealed marked upward displacement of the odontoid process through the foramen magnum compressing the spinal cord asymmetrically. The right vertebral artery was markedly constricted by the dens and the lip of the foreman magnum and yet was histologically patent. The left vertebral artery, however, was atherosclerotic and recently occluded in its mid cervical portion. Recent infarcation was seen in the cervical-medullary region, brain stem, both cerebral hemispheres and cerebellum in the posterior cerebral territories. Wallerian degeneration was present in the spinal cord.

In addition to the more common 'myelopathy', he clearly had a super-added vascular catastrophe leading to his death. The mechanism of the event as it relates to rheumatoid atlanto-axial subluxation will be discussed.

\section{Trigeminal Pain: Neurophysiological Correlates of Trigeminal Tractotomy and Carbamazepine Therapy}

B. J. Sessle and L. F. Greenwood, Toronto, Ontario

Trigeminal (V) neuralgia and some severe oral-facial pains may be successfully relieved by the administration of carbamazepine (Tegretol, Ciba-Geigy), or by a V tractotomy operation at the obex which is thought to disrupt the function of the caudalis component of the $\mathrm{V}$ spinal nucleus. In decerebrate or anaesthetized (chloralose) cats we are investigating brain stem mechanisms which may be involved in $\mathrm{V}$ pain and which might explain the effectiveness of these procedures. In the present studies, recordings were made of digastric (jaw-opening) and facial muscle reflexes evoked by innocuous (tactile or low-intensity infraorbital nerve) or noxious (tooth pulp) stimuli. Tractotomy, or reversible cold block of synaptic transmission in nucleus caudalis (Sessle and Greenwood, Brain Res. 67: 330, 1974) could depress these reflex responses to both innocuous and noxious oral-facial stimulation. Carbamazepine $(4 \mathrm{mg} / \mathrm{kg}, \mathrm{I} . \mathrm{V}$.) also caused a reversible abolition of these reflex responses, and the drug's diluent (propylene glycol) had no effect. Since recent studies indicate that the interneurones for these reflexes are located in or adjacent to the oralis component of the $V$ spinal nucleus, we have also examined the effects of these procedures on the responses of single $\mathrm{V}$ neurones in this nucleus that were recorded with microelectrodes. Tractotomy, cold block and carbamazepine could depress the responses to innocuous and noxious stimuli of interneurones and also of neurones relaying to the ventrobasal thalamus. The success of both tractotomy and carbamazepine therapy in reducing the reflex and sensory manifestations of $\mathrm{V}$ pain may therefore result from these procedures reducing the transmission of oral-facial inputs to $\mathrm{V}$ interneurones and relay neurones.

\section{CANADIAN NEUROLOGICAL SOCIETY PRIZE ESSAY}

\author{
A Pharmacological Study of Serotonergic Mechanisms \\ in Post-Anoxic Action Myoclonus (Lance and Adams Disease) \\ Jacques DeLean, Toronto, Ontario
}

Lance and Adams described the clinical and electrophysiological features of a rare syndrome of intention or action myoclonus persisting after acute cerebral anoxia. Lhermitte et al have discovered in similar cases the beneficial effect of L-5-Hydroxytryptophan (L-5-HTP), the precursor of Serotonis (5 HT). Recently, Bédard and Bouchard have reported in their case a dramatic effect of Methysergide (Sansert), a potent antagonist of $5 \mathrm{HT}$. Even if Methysergide possibly has some 5 HT-like effects in the central nervous system, this result suggests the possibility of an hyperactivity rather than a deficiency of serotonergic mechanisms in post-anoxic intention myoclonus. Other investigators have reported beneficial results of treatment with Chlorpromazine, L-dopa and Diazepam. This report is based on extensive pharmacological study of two cases of hypoxic action myoclonus in the service of Dr. J. C. Richardson. Valuable assistance was given by Dr. O. Hornykiewicz with regard to the pharmacological investigation.

Case I: A 64 year old man was examined 9 months after a crush injury to his chest which restricted his respiratory movements for 10 minutes. $\mathrm{He}$ emerged from the initial state of coma and convulsion with no dementia or paralysis but with persistent completely disabling action myoclonus and mild cerebellar signs. There were involuntary jerks of trunk and limb muscles activated by willed movements. No spontaneous or reflex visual or auditory myoclonic activity was present. Only partial control had been achieved by oral administration of Diazepam.

Case II: A 70 year old woman had suffered a respiratory arrest following intoxication with barbiturates. Her neurological examination 27 months after the anoxic incident was quite similar. Diazepam and anticonvulsant medication had only minimally suppressed her involuntary movements.

Drug trials of these two patients were evaluated by daily neurological exmination and controlled by administration of placebo.

L-Tryptophan, a precursor of $5 \mathrm{HT}$, given orally produced a moderate but definite reduction in myoclonus in both patients. Phenylezine (Nardil), an inhibitor of the monoamine oxidases, was combined with L-Tryptophan and increased its beneficial effect. Combination of L-Tryptophan and Allopurinol (Zyloprim), a blocker of Tryptophan Pyrrolase was associated with no further improvement and no detectable change in urinary excretion of 5 HIAA, the catabolite of 5 HT. Small dose of Methysergide produced a dramatic but transient improvement in one case while a higher dose exaggerated the myoclonic activity in both cases. Parachlorophenylalanine (PCPA or Fenclonine), an inhibitor of Tryptophan Hydroxylase did not significantly alter the jerky movements. Intravenous and oral administration of L-5-HTP reduced dramatically the abnormal movements. L- $\alpha$-Methyldopa Hydrazine (MK 486 or Carbidopa), a peripheral inhibitor of L-amino acid Decarboxylase, had no effect when given alone and was combined with L-5-HTP to minimize its side effects. L-dopa, at the level of $2 \mathrm{~g}$. daily used only in one patient resulted in deterioration of the myoclonic activity. In both patients, CSF 5HIAA was found to be significantly low initially and was monitored during the study.

These results will be discussed to support the suggestion that Lance and Adams disease is associated with insufficiency of central serotonergic mechanisms.

\section{The Ventromedial Nucleus: Electrophysiological Evidence for its Role as a Neuroendocrine Integrative Centre Leo P. Renaud, Montreal, Quebec}

Control of adenohypophyseal secretion is mediated by peptide hormones secreted into the pituitary portal plexus from median eminence axon terminals of hypothalamic tuberoinfundibular neurons. Electrophysiologic studies in pentobarbital anaesthetized rats utilized stimulation of these axon terminals to identify tuberoinfundibular neurons by antidromic invasion, and found most of them located within the ventromedial and arcuate nuclei and the periventricular region. Stimulation of extrahypothalamic regions (amygdala and hippocampus) known to influence adenohypophyseal secretion had excitatory and inhibitory influences on specific populations of these neurons. Axons of some 
tuberoinfundibular neurons within the ventromedial nucleus not only had median eminence terminals but also sent axon collaterals rostrally (to preoptic area) and dorsally (to medialis dorsalis of thalamus) to regions outside of the hypothalamus. These observations suggest that axoplasmic transport over these extrahypothalamic channels would be a mechanism for the known central distribution of hypothalamic peptides. These, and other connections of ventromedial neurons, provide the ventromedial nucleus with the necessary synaptic pathways to function as an integrative centre for neuroendocrine regulation.

\section{Role of Manganese in Hypothalamic Control of Prolactin and Growth Hormone}

Naohide Inoue, Martin Lis, Yasuo Tsukada, Michel Chretien and Andre Barbeau, Montreal, Quebec

Previous studies from our laboratory have demonstrated high concentrations of manganese in the hypothalamus of rat, cat, dog and man. Further dissection indicated that in the hypothalamus, the median eminence had the highest concentration of manganese in all these species Following the investigations of LaBella and collaborators in Winnipeg, who outlined the role of copper, zinc and nickel upon the control of hypothalamic hormones, we undertook to study the effect of intraventricular injections of manganese upon the secretion of prolactin and growth hormone. Albino Sprague-Dawley rats weighing $200 \mathrm{~g}$. were cannulated into the left lateral ventricle and microinjected with 25 or $50 \mu$ g. doses of manganese chloride or an equivalent volume of saline, 24 hours after the implantation of the cannula (constant injection speed 10 $\mu \mathrm{l} . / \mathrm{min}$.). The rats were killed by decapitation one hour after the injection and the brains analyzed for catecholamine and serotonin content. At the same time blood samples were collected from the trunks for radioimmuno-assay of prolactin and growth hormone. A total of 119 rats were used in the experiments. Intraventricular injection of manganese chloride caused a dose dependent increase in serum prolactin of the same magnitude as that obtained with $5 \mathrm{mg}$. $/ \mathrm{kg}$. (i.p.) of chlorpromazine, and a dose dependent decrease in growth hormone secretion. This pattern is the reverse of that obtained by LaBella with nickel and is also different from that of copper. At the time of sacrifice, manganese injections had caused a significant decrease in hypothalamic noradrenaline concentrations, but no change in dopamine or serotonin content. The present studies constitute further evidence in favour of an important role for trace metals in the hypothalamic control of neurotransmitters and hormones.

\section{Pain: A Clinicopathological Study}

G. M. Remillard, Y. Robitaille, S. Carpenter and R. Melzack, Montreal, Quebec

The precise function of the dorsal horns of the spinal cord in the appreciation of pain in man remains to be elicited. The functions that have been proposed are based primarily on studies in animal subjects.

This report describes detailed clinical anatomical and pathological correlations in a patient who, during the last 7 years of life complained of well localized pain from $\mathrm{C} 8$ to $\mathrm{T} 8 \mathrm{on}$ the left side, occuring spontaneously or elicited by light touch. All other sensory modalities were normal. At postmortem a well localized syringomyelic cavity, restricted to the left dorsal horn and without communication with the fourth ventricle was found. It selectively destroyed the dorsal hom (corresponding to Rexed Laminae I-VI), while the remainder of the spinal gray matter (corresponding to Rexed Laminae VII-X) was preserved. Other intact structures included the sensory cortex, the thalamocortical system, the spinothalamic tract, the posterior columns and the posterior roots.

These observations suggest that the spontaneous pain and hyperesthesia observed in this patient are due to the loss of inhibitory influence on the somatosensory input. The findings support the gate control rather than the specificity theory of pain.

\section{Optokinetic Nystagmus: Its Value in Otoneurological Diagnosis}

\section{S. M. Abel and H. O. Barber, Toronto, Ontario}

The primary goal of this research is the development of a noninvasive diagnostic test to discriminate first order neuron vestibular lesions from those located more centrally. Thus, we have studied op- tokinetic nystagmus (OKN) in normal subjects and in patients who either have had unilateral labyrinthectomy or have neurologically confirmed brainstem/cerebellar lesions of ischemic, neoplastic, or demyelinating type.

In routine ophthalmologic practice it is usual to test for optokinetic nystagmus using simple equipment with no facility for the control of target speed. Abnormalities are commonly identified as gross asymmetry of nystagmus in opposite directions. In our study ENG recording was used and a variety of stimulus speeds were presented. These speeds ranged from $20^{\circ}$ to $140^{\circ}$ for horizontal and vertical movement of visual targets. Our results show that the function relating the speed of the slow phase of nystagmus and the speed of movement of the stimulus is significantly different for the three groups. Specifically, for normal Ss and for patients with peripheral lesions, eye speed is an inverted $\mathrm{u}$-shaped function of target speed. For patients with brainstem disease, OKN while present, it independent of target speed. Asymmetries are exceptional for our patient population.

At present we are engaged in attempts to refine the localizing significance of the test. Our studies are concerned with examination of patients with disorders of orbital muscle movement and lesions of parietal and temporal lobes.

\section{Audiovestibular Function Tests in Children with Brain Stem and Cerebellar Neoplasms}

Jerry J. Krumlik and R. P. Gannon, Vancouver, British Columbia

Five children, aged 3 years 11 months to 14 years, with proven neoplasm of brain stem or cerebellum were studied with audio-vestibular function tests. Stapedius reflexes were abnormal in 3 cases of pontine neoplasm and in one case of cerebellar astrocytoma involving the middle cerebellar peduncle, with probable pontine infiltration, whereas they were normal in one girl with tumor of the cerebellar hemisphere and vermis. Electronystagmography (ENG) demonstrated spontaneous and positional nystagmus suggestive of central vestibular lesion and abnormal caloric responses in all five patients.

In contrast, a girl with a tumor confined to the floor of the 3rd ventricle had normal stapedius responses and normal vestibular function on ENG. Deterioration of vestibular function was shown to precede clinical signs of relapse after radiotherapy in one boy with astrocytoma of brain stem. Thus audio-vestibular tests have proved useful as a noninvasive technique in the diagnosis and follow-up of brain stem and cerebellar tumors in children.

\section{Familial Paralysis of Horizontal Gaze Associated with Pendular Nystagmus and Progressive Scoliosis}

J. A. Sharpe, J. L. Silversides and R. D. G. Blair, Toronto, Ontario

Paralysis of lateral gaze, pendular nystagmus and progressive scoliosis were manifestations of a distinctive hereditary syndrome in four siblings. Convergence during attempted lateral gaze was an inconstant feature of the horizontal ophthalmoglegia. Historical evidence suggested that the gaze palsy was acquired but we did not observe the eye movements in childhood. It may have been present at birth and undetected. Pendular ocular oscillations and progressive scoliosis, however, distinguish this disorder from all congenital and nonprogressive syndromes of horizontal gaze paralysis, either isolated (Zweifach PH et al Arch. Ophthalmol. 81: 345, 1969) or associated with facial palsy in Moebius' syndrome (Van Allen MW, Blodi FC., Neurology 10: 249,1960 ).

Bilateral continuous fascicular facial movements (myokymia) and facial contraction developed in the oldest patient. Computerized axial tomography, pneumoencephalography, and a four year period of observation provided no evidence for brain stem neoplasm or multiple sclerosis that are usually associated with facial contraction and myokymia. Electromyographic examination of his facial muscles showed bursts of periodic muscle potentials that were asynchronous in different muscles on each side of the face. A background of continuous motor unit activity was the electromyographic correlate of the sustained facial contraction. Peripheral facial nerve block at the stylo-mastoid foramen abolished the myokymia and contraction. Needle electrode examination during the block showed absence of any spontaneous mus- 
cle activity consistent with a supranuclear origin of the facial dyskinesia.

Normality of vertical gaze, convergence, levator function and pupillary constrictor reflex activity assured integrity of midbrain ocular motor function. Absence of horizontal vestibulo-ocular reflexes signified involvement of the pontine tegmentum in this unique heredofamilial syndrome.

\section{Unilateral Coronal Synostosis and its Management}

H. J. Hoffman, E. B. Hendrick, R. P. Humphreys and G. Mohr, Toronto, Ontario

Thirty-six patients with unilateral coronal synostosis treated during the past 10 years at the Hospital for Sick Children in Toronto are presented. Out of 25 patients with closure of their right coronal suture, 17 were female and 8 were male.

The most characteristic radiological finding was a greatly thickened, beaked, prominent pterion, present in 20 patients.

The results of 4 different techniques of treatment were analysed.

1) 3 patients had only a linear craniectomy along the coronal suture. The result was significantly better in the one patient with a normal pterion.

2) 17 patients were treated by removing the coronal suture down to the pterion and using this strip of bone as a supraorbital graft placed subperiosteally to correct the concavity and aplasia of this area. $9 \mathrm{pa}-$ tients without a prominent pterion had excellent results in 6 , a good result in 2 and a good result in 4 cases, whereas the 3 patients with normal pterion had an excellent result in 2 and a good result in 1 case. poor result in 2 cases. Five of these 17 patients had repeated procedures and all had a prominent pterion.

3) 9 patients were treated by removal of the frontal bone (craniotomy and reshapement of forehead vault) with morcellation into several fragments. 6 patients had a prominent pterion and had an excellent result in 2 and a good result in 4 cases, whereas the 3 patients with normal pterion had an excellent in 2 and a good result in 1 case.

4) 7 patients were treated by frontal craniotomy and additional lateral canthal advancement of the supraorbital margin which was secured by a lateral bone graft. At the time of this abstract 5 out of these 7 have had an adequate follow-up. Four of these 5 had a prominent pterion. Of these, 3 had an excellent and 1 a good result. The remaining case without a prominent pterion had a good result. The 2 recent cases both had a prominent pterion and an immediate excellent result was achieved.

Conclusion: On the basis of our results, it appears that unilateral coronal synostosis with absent or mild dysplasia of the sphenoid bone and middle cerebral fossa may benefit from coronal craniectomy and supraorbital graft. However, in cases with a marked prominent pterion, aplasia of the frontal bone and marked dysplasia of the orbit, we think that the treatment of choice is the craniotomy procedure and plastic reconstruction of the supraorbital margin by means of lateral canthal advancement and grafting.

\section{Clinical Significance of Multiple Independent Spike Foci (MISF) in Children}

W. T. Blume, London, Ontario

Adequate clinical studies of hypsarrhythmia and of unifocal spikes in children have been made. However, scant, if any, attention has been paid to MISF, a common EEG pattern occupying electrographically an intermediate position between hypsarrhythmia and unifocal spikes.

EEG's of 63 patients, less than 15 years, had spikes arising independently from non-homologous regions of each hemisphere on at least one recording. 53 patients $(84 \%)$ suffered from a seizure disorder of which 33 (52\%) had more than one type. Grand mal, unilateral clonic, atypical absence and tonic seizures were the most common forms.

Generalized motor seizures (GMS) (grand mal, tonic, bilateral clonic, infantile spasms) occurred in 48 patients (76\%). GMS afflicted $80 \%$ of patients whose EEG also contained generalized spike-waves and $70 \%$ of these without spike-waves. The incidence of GMS bore no significant relationship to the number of spike foci present, and only a slight relationship to the quantity of spikes.

20 (32\%) had normal intelligence; 20 were mildly subnormal; $23(36 \%)$ were moderately-severely subnormal. Excluding 14 patients whose re- cordings contained excess delta activity for age, the incidence of moderately severe subnormality fell to $22 \%$ (11 of 49$)$. The incidence of normal intelligence diminished from $47 \%$ with 9 or less spike foci to. $8 \%$ with 10 or more foci $(p<0.005)$. Similarly, only $15 \%$ of patients whose records contained spikes at least every 10 seconds were intellectually normal as compared to $52 \%$ of those with less frequent spiking ( $\mathrm{p}<$ 0.005).

Birth trauma and CNS infection were the most common of multiple etiologies. 31 patients had a normal neurological examination. Neurological abnormalities included hemiplegia (8), quadriplegia (7), ataxia (7), diplegia (3), and neurocutaneous syndromes (3).

MISF, although usually representing a seizure disorder, occupies an intermediate position between hypsarrhythmia and unifocal spikes regarding mental development. Moreover, there are electrographic features within this pattern with which normal and subnormal mentalities are differentially associated.

\section{Clinical Course and Leukocytic Biochemistry and} Ultrastructure in Five Girls with Cerebroretinal Degeneration

\section{G. G. Hinton, B. A. Gordon and M. Daria Haust, London, Ontario}

Five unrelated girls ranging in age from 12 to 17 years with a history of progressive mental retardation and deterioration of vison have been investigated. All patients had a normal natal and postnatal history up to age 5 or 6 years with the exception of one who at 9 months developed measles complicated by febrile convulsions and on examination was observed to have retinal hyperpigmentation with nystagmus. In the initial school years visual difficulty, clumsiness and progressive mental deterioration became apparent and all were blind by 10 years. Two of the five show severe muscle weakness. Abnormal EEG's were found in all patients; grand mal seizures began 2 to 4 years after the initial symptoms in 3 of the 5 girls, the 4th had febrile convulsions and the 5th has remained seizure free.

Leukocyte peridoxase activity assayed in 4 patients (using p-phenylenediamine as the hydrogen donor) was markedly decreased in two but within normal limits in the other two.

Ultrastructural evaluation of the peripheral leukocytes in 2 patients showed the presence of parallel membranous arrays reminiscent of, if not identical with, the fingerprint inclusions previously observed in the juvenile and infantile form of ceroid-lipofuscinoses. These inclusions were present either free in the hyaloplasm or enclosed in the (trilaminar) vacuoles.

Laboratory studies of readily accessible blood samples are valuable in the diagnosis of cerebroretinal degenerations.

\section{Glial and Neuronal Alterations in Hurler, Hunter and Sanfilippo Diseases}

\section{B. Lach and M. Daria Haust, London, Ontario}

The ultrastructural studies of the central nervous system (CNS) in genetic mucupolysaccharidoses published to date do not report in detail on glial tissue. This communication concerns itself with the results of comparative studies of glia and neurons in CNS obtained at autopsies of patients with the Hurler (4 cases), Hunter (1) and Sanfilippo (2) diseases. The neurons showed the presence of zebra bodies (ZB), granulo-membranous and membrano-cytoplasmic bodies, and vacuolar (Va) inclusions filled with granular and fibrillar substance. Intermediate forms between rough endoplasmic reticulum (RER) and lamellar bodies (LB) suggested that the latter developed from RER. Intracellular storage varied from one CNS area to the other, however, it did not show essential differences among the diseases examined. Intraglial inclusions varied with the type of cell involved, Oligo- and astrocytes contained LB (usually with periodicity different than that in neurons), lipids, lipofuscin and dense material. Astrocytes in corpus callosum formed Rosenthal fibres and showed numerous Va: some Va contained small LB. Oligodendroglia often showed myelin figures, curvilinear-like and finger-print inclusions. Monocytic microglia contained only dense homogenous bodies, neutral lipids and myelin figures. $\mathrm{Zb}$ and other 'neuronal type' inclusions were uncommon in the glia, and there was no evidence that these bodies were formed in glial cells. These microscopical findings suggest that the intracellular inclusions evolve by different mechanisms in the glial and neuronal cells. 
Familial Macrocrania - Megalencephaly versus Hydrocephalus G. V. Watters, M.D., A. M. O'Gorman, M.D. and S. Helfgott, Medicine II, McGill

The Montreal Children's Hospital

2300 Tupper Street, Montreal, Quebec H3H 1P3

The infant of child with a large head often poses a problem as to whether his head enlargement is due to megalencephaly or hydrocephalus. In most cases of megalencephaly the ventricles are not enlarged but in some instances of this disorder ventricular enlargement is seen. The inheritance of anatomic megalencephaly is usually autosomal dominant while the commonest form of hydrocephalus that associated with spina bifida is inherited at a risk rate of about 1 in 10 . A similar inheritance pattern is seen in hydrocephalus without spina bifida, while one form of aqueductal stenosis is inherited as a sex linked disorder.

Twenty children who presented with occipital-frontal circumferences (OFC) of greater than the 98th percentile for age were assessed by a) serial OFC measurements, b) skull xray, c) echoencephalography of ventricular size, d) electroencephalography and f) either pneumoencephalography or CT scanning. In addition, the OFC of siblings and parents of these patients was also recorded.

Of the 20 children who presented with large heads measuring above the 98 th percentile, 13 had normal sized ventricles. Of the 13,8 were normal on neurologic examination, and 5 had mild neurological findings. In every instance increased head circumferences were found in other family members. In 11 of the 13 it was either the child's father or the mother's brother who had a large head. This would be in keeping with an autosomal dominant inheritance with some sex limiting factor.

In the 7 other children the head was large, the ventricles were large, and all had neurologic abnormalities of mild to moderate degree. In every instance either the child's father or mother had a head circumference greater than the 98 th percentile, but had a normal neurologic examination.

Thus in all 20 children abnormal head size was compatible with a dominant disorder and suggests there families had dominantly expressed megalencephaly, which, in some cases, was associated with or caused enlarged ventricles and neurologic deficits. This inheritance pattern contrasts with the inheritance pattern expected in the commonest types of hydrocephalus with and without spina bifida. However hydrocephalus as a manifestation of megalencephaly may account for a significant number of those children presenting as hydrocephalus without spina bifida and may remain undiagnosed unless OFC measurements are made in the neurologically normal parents and siblings.

\section{Cephalocranial Disproportion}

\section{(A Complication of the Treatment of Hydrocephalus in Childhood)}

H. J. Hoffman and W. S. Tucker, Toronto, Ontario

A series of cases is presented in which children with CSF shunts for hydrocephalus have shown deterioration in neurological function despite demonstrated shunt patency, and the exclusion of other known complications seen in the management of hydrocephalus. Symptoms included irritability, headache, neck pain and vomiting. Examination revealed a variety of signs including head tilt, nystagmus, Horner's syndrome, stridor and other evidence of bulbar or lower cranial nerve disturbance, limb weakness, and sensory loss. Usually shunt obstruction or subdural hematoma was suspected, and the correct diagnosis reached after these commoner problems had been excluded.

Cerebellar tonsillar herniation was demonstrated in all cases, and was known to be an acquired feature in most, as initial studies had shown communicating hydrocephalus without hindbrain hernia in at least 5 of the 8 cases. Posterior fossa decompression has resulted in modest improvement in these patients, though follow-up is as yet brief.

A theory of the pathogenesis of this lesion is discussed, based on the concept that CSF shunting may result in a period of temporary arrest of skull growth, leading to a relative cephalocranial disproportion. After shunting, the head circumference of a number of these patients had decreased from the highest percentile range, to the lowest, rather than stabilizing in the average range. The implications of this syndrome for the management of hydrocephalus are discussed.

\section{Metabolism of Lipids in Murine Muscular Dystrophy - Neurogenic or Myogenic?}

K. P. Stricland, A. J. Hudson, J. J. Jato-Rodriguez and C. H. Lin, London, Ontario

A number of recent reports have strongly supported the view that murine muscular dystrophy (commonly used as a model for human muscular dystrophy) has a neurogenic origin (see Nature 243, 258, 1973 for ref's.). However, other studies including our own biochemical investigations do not entirely support this view (Nature 243, 258, 1973; Douglas and Dosmos, Fed Proc. 33, 402, 1974). In the work to be reported certain aspects of lipid metabolism have been examined in denervated muscle from normal mice and in dystrophic muscle from mice of the Bar Harbour strain 129. A number of parameters showed no change or similar changes. For example, measurements of enzyme activities in homogenates from denervated and dystrophic hind leg muscle of mice showed no changes for succinic dehydrogenase and cytochrome oxidase and parallel increases for monoamine oxidase (25-50\%) and lipase (125-250\%). Similarly, examination of the utilization of palmitate-1-14 $\mathrm{C}$ and palmitylcarnitine by mitochondria from the above muscles showed parallel decreases in oxidation of palmitate $(30-42 \%)$ and palmitylcarnitine (37-66\%). However, a comparable study with acetylcarnitine showed a striking difference with no change evident in mitochondria from denervated muscle and a $85 \%$ decrease in dystrophic muscle. A study of succinic dehydrogenase and the enzymes of $\beta$-oxidation in the above mitochondrial preparations showed similar findings except for acyl CoA dehydrogenase activity. The activity of the latter enzyme, which has a regulatory role in $\beta$-oxidation, was significantly diminished $(29 \%)$ in denervated muscle whereas no change was observed in dystrophic muscle. While our findings show a close parallel in a number of parameters nevertheless distinct differences were observed in denervated as compared to dystrophic muscles.

\section{A Study of Peripheral Axons and Schwann Cells in Normal and Dystrophic Mice}

\section{J. J. Gilbert, London, Ontario}

Dystrophic mice (Bar Harbour dy/dy) have been demonstrated to have abnormalities of peripheral nervous system myelination (Bradley and Jenkison, J. Neurol. Sci. 17: 227, 1973). The present study has further :xamined the pattern of myelination in lumbosacral roots and sciatic ierves in a mutant strain $\left(\mathrm{dy}^{2} \mathrm{~J} / \mathrm{dy}^{2} \mathrm{~J}\right)$ of these animals. Quantitation ltrastructural techniques have been used to assess animals during various stages of development, from the time of birth to two years of age.

Both ventral and dorsal roots show bundles of contiguous naked axons (amyelinated) throughout their entire course in the spinal subarachnoid space. The region of maximum amyelination is about midway along the course of the root. These abnormal fibers continue through a normal appearing dorsal root ganglion region peripherally down the sciatic nerve to below the level of the sciatic notch.

Many naked axons over a portion of their course acquire myelin lamellae but the sheath is often only $30 \%$ of normal thickness for axons of comparable diameter.

The axons themselves appear unremarkable but the Schwann cells, which surround the bundles of naked axons show abnormalities both in their basal lamina and in their cytoplasmic contents. In some ventral roots, regenerating axon sprouts are present.

These findings indicate that both the Schwann cells and axons are abnormal. The significance of these findings to the abnormalities demonstrated in motor end plates and skeletal muscles remains to be determined.

\section{Myopathies of Early Onset}

E. J. Gibson, V. G. Sangalang and J. A. R. Tibbles, Halifax, Nova Scotia During the past ten years, in a pediatric hospital which serves a population of approximately one million people, 23 cases of myopathy with onset before age 2 years have been diagnosed. The yield of positive diagnoses increased with more extensive use of muscle histochemistry and electron microscopy, as well as routine examination of all family members. The distinction between primary muscle disease and primary neurogenic atrophy was occasionally difficult, and at times the two were considered to coexist. 
The intelligence of the patients has usually been normal. In some patients with morphologically normal myopathies, cardiac disease may develop as a late complication. Two patients with centrinuclear myopathy pursued atypical clinical courses. Two examples of uncommon morphological changes encountered were multiple small cores ('multicore disease') and concentric laminated bodies.

Attempts at genetic counselling must be based on a firm diagnosis, although lack of long-term follow-up for the recently described 'benign' myopathies renders the task more difficult than in progressive dystrophies.

\section{Skeletal Muscle Involvement in Patients with Asymmetric Septal Hyper- trophy (Ash)}

L. P. Heffernan, E. R. Smith and V. E. Sangalang, Halifax, Nova Scotia

It is well known that cardiac involvement, either symptomatic and/or productive of electrocardiographic alterations, may occur in certain neuromuscular disorders, the latter usually being of the heredofamilial variety.

Recently it has been documented that patients presenting with idiopathic 'acquired' cardiomyopathy may demonstrate, in the absence of clinical evidence of dysfunction, skeletal muscle electromyographic and biopsy alterations. Electromyographic parameters of a myopathic nature have also been detected in patients with a particular variety of cardiomyopathy, ie., hypertrophic obstructive (asymmetric septal hypertrophy - ASH). We are unaware of any reports describing clinical or histological alterations of skeletal muscles in this condition.

Ten patients who presented for investigation had echocardiographic documentation of ASH. Five had clinical evidence of skeletal muscle involvement. Two had slightly elevated CPK levels, one of whom presented clinically with weakness.

Electromyography in 9 of 10 cases demonstrated reduction in potential amplitude and duration plus an increase in the percentage of polyphasic potentials (findings accepted conventionally as indicative of a myopathic process). Light and electron microscopic studies of muscle biopsy tissue, from both girdle and paraspinal sites, demonstrated alterations in 7 patients - cenral cores \pm target fibres, variable proliferation and altered strucutre of mitochondria. Such changes have been described previously in association with myopathic disorders of variable clinical manifestations, usually familial and of a slowly progressive nature. These findings suggest that ASH may well be part of a larger disease spectrum which results in abnormalities of both cardiac and skeletal muscle.

\section{The Myopathy of Trichinosis \\ J. G. Blain, Edmonton, Alberta}

An outbreak of Trichinella Spiralis infestation in a group of Cree Indians was investigated. Fifty-one persons were involved clinically. These ranged in age from eight to fifty years of age. Children between eight and twelve were most severely infested, five of whom required hospitalization. Two of these succumbed of their illness. The Trichinosis was not originally suspected in the two children who died.

The infestation has been traced to infested bear meat.

Twenty-one patients had detailed neurological examinations. Ten of whom showed clinical evidence of Trichinosis, ranging from mild muscle tenderness to muscle contractures to marked rigidity, and immobilizing the patients completely.

Electromyographies were performed on eight patients and showed variable myopathic process in seven. Nerve conduction velocities were normal in all but one patient, who was severely ill and who showed dispersion of the evoked potentials.

Muscle biopsies were performed in seven patients and were diagnostic in all. The pathological features of the muscle biopsy will be reported including histochemical changes as well as ultrastructural alterations.

Discussion of the variability of infestation in the various age groups will also be presented.

\section{Acromegaly and ALS}

T. J. Murray and A. H. Shlossberg, Halifax, Nova Scotia

In 1947 McCullagh and Hewlett (J. Clin. Endocrin. 7:636-643, 1947) reported three cases of amyotrophic lateral sclerosis associated with acromegaly and provided some evidence of long-term neuromuscular improvement when the acromegaly was treated. There appear to be no further reports of this association but we have recently observed concomitant acromegaly and ALS in a 44-year-old woman. She was treated first with radiotherapy but growth hormone levels did not change and hypophysectomy was carried out. At 18 months postoperatively her condition appears stable.

To assess a possible relationship of abnormal pituitary function to ALS we admitted four cases of ALS to the Clinical Investigation Unit at the Victoria General Hospital for neuromuscular and metabolic studies, including growth hormone assays, growth hormone response to glucose, insulin and L-dopa, adrenal studies, metopirone testing, EMG and nerve conduction studies, nerve and muscle biopsy, and a survey for malignancy.

We could not demonstrate any abnormality of pituitary function in ALS, suggesting that the association of acromegaly and ALS is either a chance finding, or that growth hormone may act as a non-specific factor in the 'aging' process of motor neurons as described by McComas et al (Lancet 4:1477-1480, 1973). Growth hormone may affect motor neuron metabolism in susceptible individuals, similar to the situation in some patients with carcinoma, malabsorption, electrical injuries and hyperinsulinism.

\section{Biofeedback and Focal Epilepsy}

A. R. M. Upton, D. Longmire and A. J. McComas, Hamilton, Ontario

Over the last three years, we have used intermittent biofeedback techniques to modify focal EEG activity in 10 epileptic patients who continued to receive their usual medication. During each 30 minute session, the patients tried a variety of maneouvres to decrease the frequency of their focal discharges; they received feedback in the form of auditory or somatosensory stimulation, each stimulus being triggered by a focal discharge. The performances of the patients were compared with those during control periods without feedback. In six patients, it was found that focal EEG activity could be significantly reduced with the aid of feedback and that the effect persisted beyond the experimental sessions; the improvement in the EEG was associated with clinical amelioration. In one other patient, who suffered from temporal lobe epilepsy, the seizure activity was diminished by somatosensory stimulation but was aggravated by auditory inputs.

In addition to visual inspection of EEG records, the one-line EEG activity was subjected to automatic frequency analysis, the centre frequencies being $2.5,5,10$ and $20 \mathrm{~Hz}$ respectively.

Long term objectives of these studies include the development of miniaturized 'pacemakers' to provide continuous rather than intermittent feedback. Such devices may teach the patient to recognize a sensory aura or, if absent, can provide an 'electrical' aura instead. In addition to reducing the frequency of seizures, biofeedback techniques can indicate a need for more medication or allow protective measures to be taken before a seizure.

\section{Chronic Exploration of Epilepsy by Stereo-Electroencephalography}

Jean-Marc Saint-Hilaire, Guy Bouvier, Monique Frize and Jean Lymburner, Montreal, Quebec

The localization of an epileptogenic area by inter-ictal spike activity is well known. Nevertheless, using this criterion only can lead to serious errors, especially where surgical treatment is considered. Bancaud demonstrated the importance of recording epileptic seizures in the precise determination of the origin and diffusion of the epileptic discharges. He coined the term Stereo-electroencephalography to stress the importance of using stereotaxic techniques in the precise implantation of depth-electrodes in the desired structures.

Moreover, the clinical events during the attack are as important as the electrical phenomenon. The manifestations of the seizure are fleeting and complex and are usually accompanied by much emotion. It is therefore essential to have a system which will seize the clinical aspect of the attack and thus allow precise electro-clinical correlations, in view to locate the zone responsible for the epileptic process.

With this in mind, a system was developed at the EEG laboratory of Notre-Dame Hospital which permits long recording sessions performed in the most physiological conditions possible. Then data on the different elements of the epileptic seizure can be collected and reproduced as they occurred, thus allowing good electro-clinical correlations. 
This system incorporates:

1. A 16 channels wireless telemetry system (PAM-FM) and another system transmitted by wire to two 16 channels EEG recorders.

2. A video and audio system, consisting in two remote controlled cameras, microphone, and video tape recorder.

3. A system of synchronisation between the EEG recorder and the video tape recorder, allowing correlations between the two with a precision of the order of a tenth (1/10) of a second.

Examples will be presented to show the capabilities of the system.

\section{Chronic Multiple Depth Electrodes in 'Bitemporal Epilepsy':} A Clinical Appraisal in 10 Patients

A. Olivier, P. Gloor, J. Ives, C. Thompson and F. Andermann, Montreal, Quebec

Ten (10) consecutive patients suffering from intractable cerebral seizures with an E.E.G. pattern suggestive of bitemporal epileptic activity were submitted to chronic-spatial depth recordings. Multiple contact stainless-steel wire electrodes were implanted stereotaxically and bilaterally in the temporal lobe cortex, amygdala, hippocampus and parahippocampal gyrus for a period of time averaging three weeks. Continuous day and night recordings were carried out by interconnecting the patient to either a standard 16-channel E.E.G. machine or to an 8- or 16-channel E.E.G. telemetry transmitter.

A special computer programme can be used to recognize and store the actual seizure discharges. An average of 71.3 seizures were recorded per patient over an average implantation period of 22 days: of these, $51.3 \%$ (36.6) were accompanied by clinical manifestations and $48.7 \%$ (34.7) consisted of 'electrographic seizures' without obvious clinical correlations. In all patients, inter ictal epileptiform activity was present bilaterally but predominated on the side of maximal seizure activity.

In all the patients studied, the onset of the seizure discharge was overwhelmingly (86.1\%) lateralized to one side of the brain. Decision to operate was based on correlations of these E.E.G. findings with the results of the intracarotid Amytal memory tests, neuro-psychological and $\mathrm{x}$-rays findings. Out of the 10 patients, 9 were submitted to standard temporal lobectomy, including resection of the amygdala and anterior hippocampus.

A short follow-up is given to indicate that some of these patients, once rejected as surgical candidates, can expect a reduction in their seizure tendency comparable to that of patients with so-called "unilateral temporal lobe epilepsy'.

\section{Septal and Caudate Influences on the}

\section{Activity of an Acute Amygdaloid Epileptogenic Focus}

R. Fariello and O. Hornykiewicz, Toronto, Ontario

The study has been carried out on immobilized, artifically ventilated cats in which an acute epileptogenic focus was induced in the nucleus centralis amygdalae by stereotaxic injection of conjugated estrogens (Premarin(1). In these animals as in controls (non epileptic cats) the effect of the electrical stimulation of the head of the caudate nucleus and of the medial septal nuclei was investigated. In control animals the only change in the biolectrical activity of the homolateral amygdala was the appearance of slow waves during septal stimulation (rectangular pulses of $1 \mathrm{msec}$ duration, $>1.5 \mathrm{~V}, 1-5 \mathrm{~Hz}$ ). In contrast in animals with an epileptogenic amygdaloid focus marked changes of the focal bioelectrical activity of the homolateral amygdala occurred during septal and caudate stimulations. Low frequency septal stimulation induced a driving in the amygdaloid spiking. High frequency stimulation sets applied to the septum constantly evoked a seizure. Upon low frequency caudate stimulation no changes were detectable in the amygdala activity even when, by raising the stimulation voltage up to $20 \mathrm{~V}$, cortical caudate spindles were elicited. (Caudate spindles have been assumed to be the EEG expression of the activation of an inhibitory "caudate loop' ending to the neocortex.) With high frequency sets ( $>30 \mathrm{hz},>1.5 \mathrm{~V})$ the caudate exerted a clear inhibitory influence on the interictal epileptiform activity of the homolateral amygdala; this effect often outlasted the duration of the stimulation. Both after septal and caudate stimulation a delayed effect was often noted, contrary to the initial one. This delayed response is interpreted as being due to the antidromic activation of other cerebral structures which in turn may exert their influence on the amygdala. The possible neurophysiological and neurophar- matological implications of the above data are discussed and a relationship between the effect observed under the present experimental conditions and the possible role of caudate nucleus and septum in epilepsy is considered.

\section{Localization of Brain Structure through Stereoencephalography} Guy Bouvier, Jean-Marc Saint-Hilaire and Gabor Szikla, Montreal, Quebec

Stereo-electroencephalography exploration (S.E.E.G.) of focal epilepsy cases using 8 to 12 multilead electrodes recording various parts of the brain led to extensive studies on stereotactic X-ray localization of cortical target structures. Results of this study were published in 1967. Obviously the best way of localization is the direct visualization of a structure as can be obtained by contrast X-ray studies such as pneumoencephalography, performed in stereotactic conditions, e.i.: orthogonal teleradiography, the patient's head being fixed in the stereotactic frame. Such direct localization is however limited to some structures such as hippocampus, amygdala, calcar avis or sulci of the interhemispheric surface. This led to the establishment of an indirect stereotactic localization system based on the bicommissural (AP-PG) line and to overall dimensions of the brain.

The proportional grid-system developed in these studies allowed for a statistical definition of the variability area of several important cortical structures, such as the rolandic primary motor area, frontal and temporal convolutions, supplementary motor area, course of motor fibers and optic radiations in the white matter, etc. Our present work aims to add some vascular landmarks for cortical localizations giving the possibility to fix inside the statistically defined band of variability the actual situation of some cortical structures in the given individual.

At first sight, the course of the cortical arteries seems to be - and indeed is - very variable without any stable relationship to sulci, convolutions and to known landmarks as the AC-PC line, so as to make them apparently unfit to add more precision to cortical localization. However, a study of bilateral stereotactic carotid angiographies done in surgical epilepsy cases before electrode-implantation has shown that some characteristic loops, apparent crossing of branches, changes in direction showed up regularly in the same areas of our stereotactic grid. In order to understand the anatomical meaning of these rather constant features, we undertook the study of the anatomo-radiological correlations of the cortical branches of the middle cerebral artery.

\section{A Propos de Trois (3) Cas de Dysgerminome}

Jacques Francoeur, Gerald LeBlanc et Michel A. Copty, Paris, France Depuis octobre 1972, nous avons eu l'occasion de traiter dans le Service de neurochirurgie de l'Hôpital de l'Enfant-Jésus, trois (3) patients porteurs d'un dysgerminome intra-cérébral.

L'histoire clinique et l'évolution de ces patients nous apparaissent d'un grande intérét.

En octobre 1972 une patient de 16 ans présentant un retard staturopondéral, nous est référée pour un syndrome d'hypertension intracrânienne. Depuis trois (3) ans elle présentait une polyurie de même qu'une polydypsie.

L'investigation neuroradiologique a démontré la présence d'une tumeur de la partie postérieure de troisième ventricule et la patiente fut traitée à l'aide dérivation ventriculo-péritonéale puis par la suite irradiée.

Quelques mois plus tard, la patiente est réadmise à cause de l'apparition rapide d'un syndrome d'hypertension intra-crânienne avec nystagmus.

Cette fois l'investigation neuroradiologique démontre la disparition complète de la lésion de la partie postérieure du troisième ventricule avec une tumeur localisée dans la quatrième ventricule pour laquelle elle est soumise à une exploration.

Une immense tumeure remplissant le quatrième ventricule était alors enlevée.

II s'agissait d'un dysgerminome.

La patiente est traitée à l'aide de chimiothérapie puis est réadmise quelques mois plus tard dans un tableau d'hypertension intracrânienne. La patiente décède rapidement.

Notre second cas est celui d'un garçon de 17 ans admis pour investigation d-une baisse rapide de la vision chez qui un diagnostic de diabète néphrogénique avait été porté quelques mois auparavant. 
L'investigation neuroradiologique complète est peu concluante. Une exploration de la région des nerfs optiques et du chiasma de même que du troisième ventricule à sa partie antérieure est considérée comme peu concluante sauf peut-être pour une augmentation de volume du nerf optique gauche et du chiasma.

Le patient évolue par la suite favorablement, son diabète dit néphrogénique étant contrôlé.

Il est réadmis quelques mois plus tard avec un débalancement électrolytique important et il décède peu de temps après son admission.

Notre troisième patient est âgé de 9 ans et est admis en octobre 1974 pour un syndrome d'hypertension intracrânienne évoluant dupuis cinq (5) semaines.

L'investigation neuroradiologique démontre la présence d'une tumeur dans la partie postérieure du troisième ventricule. Le patient est soumis à une dérivation ventriculo-péritonéale puis par la suite la tumeur est abordée directement puis une exérèse sub-totale est pratiquée.

La patient est par la suite soumis à un traitement de radiothérapie. L'évolution jusqu'à date est excellente.

Nous aimerions discuter du mode de présentation clinique de ces trois (3) cas de même que de l'investigation neuroradioloque qui a été faite chez eux.

La pathologie de ces lésions de même que leur traitement seront par la suite discutés.

\section{Effects of Ketamine on rCBF and Brain Metabolism} D. Simard, Quebec, Quebec

Ketamine anesthesia has been widely used in recent years especially as an anesthesia agent during diagnostic procedures in neurological patients. Even if some authors $(1,2)$ have reported a marked increase in cerebrospinal fluid pressure and even an increase cerebral blood flow (CBF) (3) with Ketamine, these effects are still poorly understood.

We planned to determine if ketamine modified the CBF and metabolism in patients in whom it did not induce epileptic activity $(4,5)$. The study was carried out with ten patients. CBF was measured using the Xenon-133-intra-carotid injection technique and the Meditronic 35 detector apparatus. Measurements of regional cerebral blood flow (rCBF) were made before the intra-venous injection of $2 \mathrm{mg} / \mathrm{kg}$ of Ketamine, then at 1,15 and 30 minutes after injection. The cerebral metabolic rate of oxygen $\left(\mathrm{CMRO}_{2}\right)$ was also calculated.

Ketamine increases rCBF markedly mostly in patients with a normal cerebral cortex. This increase can be as high as $200 \%$. In patients with moderate cortical disease as in pre-senile dementia the increase is from 75 to $100 \%$. It does not increase rCBF in patients having a severe loss of cerebral cortex. Ketamine induced epileptic electroencephalographic discharges in only one of our patients. The increase in $\mathrm{rCBF}$ associated with the use of ketamine is maximal at 15 minutes after injection. We believe that this increase in $\mathrm{rCBF}$ is not the result of a direct vasodilatating action of the drug, but is the result of an increased cerebral metabolism as the $\mathrm{CMRO}_{2}$ increases after the injection of Ketamine.

It is concluded that Ketamine increases the neuronal activity of the brain, bringing a marked increase in $\mathrm{CBF}$, hence raising the intracranial pressure. This drug should then be used with extreme cautions especially in neuro-diagnostic procedures if intra-cranial hypertension is or should be suspected.

\section{Pseudo-Parkinsonism - A Common Pitfall \\ Oscar Kofman, Toronto, Ontario}

Since the advent of more effective therapy for Parkinson's Disease, particularly during the past six years, we have encountered an interesting variety of neurological disorders in patients who have specifically been referred for the treatment of conditions that were initially considered to represent Parkinsonism.

In some of these patients the presenting symptoms at times appeared to closely resemble certain of the common features of Parkinson's Disease but the neurological deficit was subsequently shown to represent a wide spectrum of generally unrelated disorders of the nervous system.

To this broad and multifactorial group of Parkinson-like disorders we have applied the name Pseudo-Parkinsonism because of the initial suggested identification with Parkinson's Disease.
In particular we are referring to a varied group of neurological conditions some of which are common, and some of which are quite rare which have presenting clinical manifestations that include: tremor, rigidity, bradykinesia, gait disorder and mild dementia, all of which are frequently first associated with Parkinsonism.

Subsequently following further clinical observation and at times after extensive investigation, some of these disorders have been identified in the following categories.

1. benign essential tremor, with initial onset of tremor.

2. normal pressure hydrocephalus, with initial onset of gait disorder with or without mild dementia.

3. progressive supranuclear palsy with rigidity, gait disorder and dementia.

4. subacute sclerosing panencephalitis with rigidity, bradykinesia, tremor and eventual dementia.

5. cerebral cortical atrophy with rigidity, bradykinesia, tremor and dementia.

6. drug induced dyskinesia with involuntary movement, tone change and gait disorder.

7. ataxia paradoxica with gait disorder and tremor.

8. hysteria with involuntary movements, rigidity and gait disorder.

9. diffuse cerebral vascular disease with gait disorder and rigidity.

10. Jacob-Creutzfeldt disease with gait disorder and tremor.

11. heptaolenticular degeneration with onset of tremor.

The purpose of this presentation is to emphasize some of the common pitfalls in the diagnosis of Parkinson's Disease and to illustrate several of the more interesting and unusual problems that we have encountered in this Pseudo-Parkinsonism group.

\section{Recurrent Encephalopathy Associated with Hashimoto's Disease}

B. R. Best, N. B. Rewcastle and R. M. Armstrong, Toronto, Ontario

Recurrent encephalopathies are well recognized in association with specific disease entities; however, they may occur without such association and then provide diagnostic difficulties. Recurrent encephalopathy associated with Hashimoto's disease, though rare, has been described. Its occurrence as the presenting feature before clinical manifestations of thyroid dysfunction appear is to be emphasized. The following clinical pathological study illustrates this.

A 23 year old female had three episodes of encephalopathy of undetermined origin over a 2 year period culminating in sudden death. Characteristic were lateralizing neurological deficits, myoclonic and major seizures, stupor and behavioural changes, all of which were transient. The general physical examination was always normal. How ever, the ESR and the CSF protein were consistently elevated, while of all the special studies performed, only the EEG and brain scan were abnormal, the latter demonstrating a diffuse uptake on her final admission.

Necropsy showed diffuse brain swelling but no specific morphological abnormality. The thyroid gland, though normal in size showed ex tensive Hashimoto's thyroiditis while post-mortem serum analysis gave significant elevations of antihyroglobulin antibody.

The nature of the recurrent encephalopathy will be discussed especially in respect to the post-mortem serum and fluorescent antibody studies on brain and other organs.

\section{Physiological Consequences of Neurofibrillary Degeneration}

\section{R. Crapper and G. J. Tomko, Toronto, Ontario}

The neuronal dysfunction associated with neurofibrillary degeneration in Alzheimer's disease is unknown. Experimentally induced neurofibrillary degeneration following intracranial injection of AICI3 is accompanied by progressive and selective deficits in short-term retention and acquisition (Crapper and Dalton, 7th C.C.N.S., 1972). To assess the effect of aluminum induced neurofibrillary degeneration upon neuronal activity, comparisons of the spike discharge pattern of 225 single units from 9 aluminum treated cats were made with 185 neurons from 13 untreated cats. At aluminum concentrations in the range of 4 to $6 \mu \mathrm{g} / \mathrm{g}$ dry weight (normal: $1.4+0.4 \mu \mathrm{g} / \mathrm{g}$ ) a selective absence of neurons with spontaneous mean discharge frequencies between 7 and 12 spikes/sec was observed in visual cortex. Furthermore, analysis of the responses to identical visual stimuli indicated a significant decrease 
in the variability of spike discharge and evidence for disfacilitation and disinhibition of the functioning units. Based on this evidence a model of neuronal dysfunction associated with experimental neurofibrillary degeneration will be discussed. In addition the data further support the possibility that the elevated aluminum concentrations found in Alzheimer's disease (Crapper et al., 8th C.C.N.S. 1973) may be in the neurotoxic range for human brain.

\section{Parkinson-Dementia Complex with $150 \AA$ Sized, Straight Filaments A New Entity}

D. King and N. B. Rewcastle, Toronto, Ontario

Recent ultrastructural and biochemical observations are defining more precisely the structure and function of neurofibrillary elements in health and disease. Pathologically, the $100 \AA$ filament, the $220 \AA$ twisted tubule and the $150 \AA$ straight filament have become associated with experimental models and specific disease entities, even though the pathophysiology to this point in time remains unclear.

The intraneuronal aggregation of $150 \AA$ straight filaments has so far only been described in Progressive Supranuclear Palsy. We wish to report their occurrence in a second disease entity characterized by a subacute progressive course of dementia and Parkinsonian features in a middle-aged male. The central nervous system at autopsy demonstrated diffuse neuronal involvement by neurofibrillary tangles without the occurrence of the senile plaques. Ultrastructurally, these neurofibrillary tangles proved to be composed of aggregates of $150 \AA$ straight filaments.

\section{Quantitation of Histologic Changes in Hippocampi of Aged Brains Melvyn J. Ball, London, Ontario}

A previous morphologic study (Dayan \& Ball, J. Neurol. Sci., 1973) suggesting that neurons containing neurofibrillary tangles of Alzheimer have a decreased metabolic rate prompted a quantitative analysis of tangle-formation in the hippocampal cortex of a series of autopsied brains from controls of various ages and from demented patients. Visualization of tangles in Congo red-stained sections was facilitated by using polarized light and a second-order red lambda filter (Stokes \& Trickey, J. Clin. Path., 1973). Microscopic fields of serially sectioned samples were sequentially screened with a semi-automated sampling stage microscope. Photographic enlargements of slides permitted the use of a computerized digitizer to measure area of grey matter analyzed. Tangle-counts were thus expressed both as raw numbers per hippocampal formation and as tangled neurons per volume of temporal cortex. While the degree of neurofibrillary tangle formation did not correlate with the brain weight, the size of the ventricular system, or the amount of cerebral atherosclerosis, a strong correlation was found between the hippocampal tangle index and (1) the age of the patient (2) the mental status at time of death (especially in Alzheimer's disease). Topographical analysis of the tangle-bearing neurons within each hippocampus prompted an hypothesis to explain the distribution seen. It is proposed that a disturbance of cerebrospinal fluid dynamics, by impairing axoplasmic flow in hippocampal efferent neurons, may result in the tangle-formation which underlies the memory defect of dementia.

\section{Neurological and Neuropsychological Assessment}

\section{of Three Patients with Lesions of the Tertiary Speech Area of Penfield}

John Gilroy and Melvin L. Schwartz, Detroit, U.S.A.

Changes in speech and/or language behaviour upon stimulation of the supplementary motor area have been reported by Brittner (1940) and Penfield and Welch (1951). Penfield and Roberts (1959) have reported that stimulation in this area could produce repetition of words and syllables as well as sustained vowel cries. They therefore considered this to be another (tertiary) speech area, in addition to Wernicke's and Broca's areas. Interference with speech has also been provoked by stimulation in this area. This particular cerebral region is bounded by the superior and medial aspects of area 6 in the Brodmann system. It is interesting that vocalization may occur during stimulation of this area in either the dominant or non-dominant hemisphere. This paper presents the neurological and neuropsychological assessment of three patients with lesions located precisely in this region.
The first patient is a 45 year old, white, right-handed female with a small arteriovenous malformation located in the supplementary motor region.

The second patient is a 19 year old, white male with a gunshot wound in the left hemisphere producing specific damage to the supplementary motor region.

The third patient is a 25 year old female who had a meningioma producing pressure on the supplementary motor region.

A brief summary of the case histories, neurological findings and arteriographic findings will be given in each of these three cases. This will be followed by the summary of the neuropsychological evaluation in each case and a description of the language problems experienced by each patient. Examples of abnormalities in speech function as taken from the Eisenson Aphasia Screening Test will be presented by tape recordings.

A brief discussion of the analysis of the language deficits found in these three patients will be presented as viewed in the light of a) premotor syndrome (described by Luria-1966) and b) the neuropsychological abnormalities described in each case.

\section{Recovery in Aphasia}

Andrew Kertesz and Patricia McCabe, London, Ontario

Spontaneous recovery from aphasia was investigated with a scorable aphasia test designed for the neurological clinician. The rate of recovery is known to be influenced by age, the time elapsed from cerebral insult, and the nature and extent of the lesion. These variables were carefully controlled and only patients whose initial examination was within 45 days of onset were included in this study (mean: 15 days). Cerebral vascular accidents (CVA's) and traumas were studied separately. Patients were followed at intervals of three and six months, then yearly, some up to five years from their first test.

The language function was assessed in terms of spontaneous conversational speech, information content, fluency comprehension, repetition, naming, and responsive speech. Patients were classified into subgroups of Global, Broca's, Wernicke's, and Conduction Transcortical Anomic Aphasias, according to taxonomic criteria based on their scores.

Analysis of recovery pattern had a higher rate in Wernicke's aphasia than in Broca's, but some Jargonaphasics improved little. Global had the worst prognosis, Conduction and Anomic groups the best. The severity of initial impairment is a good predictor of outcome, except in a few notable cases. Transformation patterns indicate that Anomic aphasia is a common end-stage in recovery.

\section{Visual Evoked Response to Patterned Stimulation}

S. J. Purves and M. D. Low, Vancouver, British Columbia

The visual evoked response (VER) to patterned stimuli has become an important tool in electrographic tests of visual function. The pattern response has some clear advantages over the previously more widely used flash evoked response. It can be presented to selective parts of the visual field and the latency of some of the components of pattern VER appear to be much more consistent across the population.

The data reported here were recorded from both patients and normal controls using a variety of methods of pattern stimulation, including different geometric forms and a computer controlled alternating checkerboard pattern which could be selectively activated for each quadrant of the visual field. The response was recorded at a number of scalp locations to map the distribution of some of the VER components.

The different geometric shapes provoked VER's that were significantly different in configuration and this difference seems to depend at least partly on the symbolic meaning of the stimuli, and not only on physical parameters of the form such as orientation of lines and corners. The VER's produced by the alternating checkerboard pattern were most consistent between subjects than those from the shapes or plain flash and selective partial field stimulation with this technique appears clearly to reflect the retinotopic organization of the visual cortex.

The application of these techniques to the study of patients with a variety of visual system disturbances including demyelinating disorders will be discussed. 


\section{ALEXANDR IVANOVICH ARUTIUNOV 1904 - 1975}

Alexandr I. Arutiunov who was Chief of Neurosurgery at the Burdenko Institute in Moscow has died. He was a leader in many of the subdivisions of the practice of neurosurgery, the treatment of brain tumors by both surgery and radiation and the treatment of vascular diseases to name but a few. He gave generously of his time and capabilities for the promotion and development of international neurosurgical societies where his quick mind and ready humour were greatly appreciated. His personal warmth, charm and wit were a constant source of pleasure to his friends. His article on The Mechanical Factors Influencing Cerebral Vascular Spasm was a masterpiece of observation, investigation and deduction beautifully presented and illustrated starting with his first proposal that the small strands running to the subarachnoid arteries were not put there by sheer chance and did not represent simple continuations of meningies.

The tremendous growth of the Burdenko Institute and of all Russian Neurosurgery over the past twenty years was to a great extent due to the driving force, guidance and brilliance of Professor Arutiunov.

\section{ARTHUR EDWARD CHILDE 1902 - 1975}

On July 22, 1975 Arthur Childe died after a lengthy illness. He was born in London, England and was a graduate of the University of Manitoba Medical College in 1925. He had been the Radiologist at the Children's Memorial Hospital, Montreal from 1931 to 1945 and Radiologist at the Montreal Neurological Institute from 1934 to 1945. He was a Major with the R.C.A.M.C. No. 1 Neurological Hospital from 1940 to 1945.

Dr. Childe was also associate professor of Radiology, University of Manitoba, Medical College since 1947, Radiologist of Children's Hospital, Winnipeg since 1947 and Associate Radiologist at the Winnipeg General Hospital since 1946. He was a past president of the College of Physicians and Surgeons of Manitoba, past first vice-president of the American Roentgen Ray Society, past president of the Canadian Association of Radiologists and past president of the Winnipeg Medical Society.

Arthur Childe was a superb radiologist and desened his international reputation. His early observations and writings on pneumoencephalography, myelography and skull and spine X-Rays are now fundamental facts used by neuro-radiologists everywhere.

His daily work was consistent, highly regarded and done without fanfare. On many occasions he resolved a difficult clinical problem and everyone who worked with him grew more dependent on his skills.

Arthur was somewhat shy and his teaching was more by example than rhetoric. The reliability of what he said and saw was beyond question. He was a good friend and a great doctor.

He is survived by his wife, Emma Childe, his son, Dr. Edward Childe, and daughter-in-law Christina, as well as three grandchildren.

\section{MICHAEL G. SAUNDERS 1920 - 1975}

The field of electrophysiology suffered a great loss on April 4th, 1975 with the sudden passing of Michael Saunders. His dedication and enthusiasm to the many facets of his profession will be sorely missed. From his earlier days as a worker and lecturer in experimental physiology in England to a position of Professor of Physiology at the University of Manitoba, his accomplishments mounted. He was instrumental in the formation of the Canadian and American technologists societies as well as on an international basis. His expertise in electronics was always in evidence. He was responsible for setting up and directing the Computer Facilities at the University of Manitoba in Winnipeg. His contributions to all levels of his profession will be a lasting tribute to his memory. He was known internationally in electroencephalography. 